\title{
ANÁLISE MULTIVARIADA E CARTOGRAFIA DE SÍNTESE NO ESTUDO DA EROSÃO
} DOS SOLOS

\author{
Eduardo Rodrigues Viana de Lima ${ }^{1}$ \\ Sérgio dos Anjos Ferreira Pinto ${ }^{2}$ \\ Paulo Milton Barbosa Landim ${ }^{3}$
}

Resumo: O trabalho teve como objetivo avaliar a espacialização do potencial natural da erosão do solo, no contexto do modelo EUPS (Equação Universal de Perdas de Solo), através da utilização de técnica estatística multivariada e de um Sistema de Informação Geográfica (SIG), em uma microbacia hidrográfica localizada na porção leste do Estado da Paraíba. $O$ fator erodibilidade do solo foi gerado a partir de análise geoestatística de dados obtidos indiretamente, em ambiente SIG. Os fatores erosividade da chuva e práticas conservacionistas foram considerados constantes para toda a área, e inseridos manualmente no SIG. Os fatores declividade e extensão de vertentes, obtidos manualmente em cartas topográficas na escala 1:25.000, foram inseridos, também manualmente, no SIG. O fator uso da terra foi obtido por interpretação visual de fotografias aéreas e inserido manualmente no SIG. A formulação da EUPS foi aplicada em SIG para gerar mapa de potencial natural de erosão, e utilizando os mesmos fatores da EUPS foi utilizada a técnica estatística multivariada da análise fatorial das correspondências. Os resultados obtidos mostraram que é possível utilizar essa técnica estatística para integração e espacialização de dados originalmente numéricos utilizados em formulações matemáticas que permitem gerar mapa de sintese.

Palavras-chave: erosão; cartografia de síntese; análise multivariada; SIG.

\section{Multivariate analysis and cartographic synthesis in the study of soil erosion}

\begin{abstract}
This work aimed at evaluating the spatialization of the natural potential for soil erosion in the context USLE (The Universal Soil Loss Equation) by the multivariate statistics technique and the Geographic Information System (GIS) of a micro river basin located at the east portion of Paraiba estate. The erosion factor was created from geostatistical data analysis indirectly obtained in GIS environment. The erosion factors of rain and conservationist practice were considered regular for the area and manually inserted in GIS. Declivity and slope extension factors were manually obtained by topographic maps in 1:25.000 scales and also manually inserted in GIS. The soil use factor was obtained by visual interpretation of aerial photographs and manually inserted in GIS. The USLE formulation was applied in GIS to generate a map of potential for natural erosion and using the same USLE

\footnotetext{
${ }^{1}$ Possui graduação em Geografia pela Universidade Federal da Paraíba (1984), mestrado em Sensoriamento Remoto pelo Instituto Nacional de Pesquisas Espaciais (1990) e doutorado em Geografia pela Universidade Estadual Paulista Júlio de Mesquita Filho (2000). Atualmente é professor Associado da Universidade Federal da Paraíba. Tem experiência na área de Geografia, com ênfase em Quantificação em Geografia, atuando principalmente nos seguintes temas: Geoprocessamento, Geografia, Sensoriamento Remoto, Cartografia, Análise Geoambiental.

${ }^{2}$ Possui graduação em Geografia pela Universidade Estadual Paulista Júlio de Mesquita Filho (1969), mestrado em Sensoriamento Remoto pelo Instituto Nacional de Pesquisas Espaciais (1981), doutorado em Geografia (Geografia Física) pela Universidade de São Paulo (1991) e Livre-Docente pelo IGCE/UNESP/Rio Claro (1996). Atualmente é Professor Titular (desde 07/04/2011) da Universidade Estadual Paulista UNESP/Rio Claro. Tem experiência na área de Geociências, com ênfase em Recursos Hídricos e Manejo de Bacias Hidrográficas, atuando principalmente nos seguintes temas: Sensoriamento Remoto, Geoprocessamento, Uso da terra, Erosão do solo e Modelos preditivos.

${ }^{3}$ Formado em Geologia pela Universidade de São Paulo em 1961, doutorado em Estratigrafia nessa universidade em 1967. Fez toda a sua carreira acadêmica no campus da Universidade Estadual Paulista em Rio Claro e se aposentou, como professor titular, em 1998. Desde 1999 é professor voluntário do Departamento de Geologia Aplicada desse mesmo campus.
} 
factors the statistic technique of multivariate factor analysis of the correspondences was used. The achieved results showed that it is possible to use this statistic technique to integrate spatialization data originally used in mathematical formulations to generate synthesis map.

Keywords: erosion; cartographic synthesis; multivariate analysis; GIS.

\section{INTRODUÇÃO}

O melhor conhecimento do comportamento de fenômenos ambientais de abrangência espacial é buscado por diferentes áreas, com o intuito de possibilitar a modelagem espacial, previsão de acontecimentos, assim como a dinâmica desses fenômenos.

Para que isso possa ser levado a efeito, é necessário que haja o conhecimento da área de ocorrência de certas variáveis ambientais, no sentido de que as mesmas possam ser avaliadas por intermédio de registros e como informações espaciais.

A espacialização de variáveis ambientais pode ser realizada de diferentes maneiras, entre as quais através de produtos de sensoriamento remoto (aéreo e orbital), de produtos cartográficos e também através de técnicas de estatística espacial, com base em observações diretas no campo, os quais apresentam diferentes níveis de dificuldade e detalhe.

Em se tratando de espacializar elementos do ambiente, os registros de sensoriamento remoto são de grande valia pela rapidez que permitem a identificação destes, pelo caráter essencialmente espacial apresentado pela informação deles retirada e pela periodicidade de obtenção desses produtos, fator importante no estudo da dinâmica ambiental, notadamente no que diz respeito à cobertura e o uso da terra.

Entretanto, certos aspectos importantes desses elementos, muitas vezes não podem ser identificados, haja vista estarem relacionados com propriedades intrínsecas do objeto analisado, só conhecidas por exame direto.

No sentido de permitir a espacialização de propriedades intrínsecas dos elementos do meio físico, a estatística espacial permite, a partir de um certo número de dados (amostras), conhecer a variabilidade espacial desses elementos. Com isso possibilita uma análise do seu comportamento espacial, o qual pode ser integrado com outras informações espaciais de forma a gerar modelos mais ou menos complexos da realidade. Constitui, portanto, técnica que permite a geração de modelo estocástico, através do qual podem ser conduzidas 
análises sobre as variações nos fatores que não podem ser medidos com mais detalhe, mas onde se julga que o uso de um valor médio poderia levar a previsões inadequadas (Christofoletti, 1999).

Apesar do custo financeiro e do tempo para a obtenção dos dados, a estatística espacial mostra-se de grande importância, visto que possibilita a espacialização de propriedades intrínsecas dos elementos do meio ambiente que apresentam variação contínua no espaço, propriedades essas que não podem ser definidas apenas pela análise de caráter ambiental dos elementos analisados.

Informações de elementos dos meios físico e antrópico, obtidas com sensoriamento remoto, documentos cartográficos ou estatística espacial, podem ser combinadas entre si com o suporte da aplicação de modelos lógicos de base física ou matemático-estatísticos. $\mathrm{Na}$ prática, isto pode ser operacionalizado por meio dos Sistemas de Informações Geográficas (SIG's), que permitem a integração de informações georreferenciadas ao território, no sentido de possibilitar a obtenção de modelos espaciais da realidade.

Dentre os fenômenos que ocorrem em um determinado ambiente e podem ser modelados espacialmente segundo a lógica de um SIG, destaca-se a erosão hídrica, que tem levado um número crescente de cientistas a estudá-la sob diferentes enfoques, entre os quais o da sua avaliação em termos de potencial natural e de sua expectativa de ocorrência, com enfoque previsional, para subsidiar o planejamento do uso da terra, notadamente na zona rural.

O desenvolvimento de modelos empíricos de predição da erosão, a exemplo do modelo da Equação Universal de Perdas de Solo (EUPS), possibilitou quantificar os parâmetros físicos responsáveis pelos processos erosivos, destacando-se a erodibilidade do solo, erosividade da chuva, declividade, comprimento de vertente, cobertura vegetal do solo e seu manejo e as práticas conservacionistas. Esses parâmetros são definidos quantitativamente e podem ter expressão espacial, vez que dizem respeito à cobertura pedológica, pluviosidade, topografia e ocupação das terras e seus manejos conservacionistas.

Os parâmetros individualizados e expressos espacialmente podem ser manipulados, seguindo-se a lógica da formulação do modelo, no sentido de fornecerem um resultado quantitativo que exprime o potencial de erosão ou a expectativa de perdas de solo.

Pesquisas têm sido desenvolvidas para estimar quantitativamente os parâmetros da EUPS, entre eles destaca-se a determinação indireta da erodibilidade do solo para as condições ambientais brasileiras, no sentido de possibilitar a mais ampla utilização daquele modelo. 
Entretanto, a definição desse parâmetro é feita, em geral, a partir de observações pontuais como representativas de unidades de solo, sem levar em consideração que este apresenta variabilidade espacial. Além disso, é utilizado um único valor do parâmetro erodibilidade para as unidades de solos, ocasionando alterações bruscas entre diferentes unidades de mapeamento. Na realidade ocorre uma transição entre essas unidades, fato que pode ser verificado por meio dos métodos de espacialização geoestatísticos.

$\mathrm{Na}$ avaliação de fenômenos relativos ao meio físico, a exemplo da erosão dos solos, há a possibilidade do uso de modelos do tipo "caixa-preta", que permitem obter previsões sobre os outputs com base nos dados dos inputs, mas sem explicitamente enunciar quais são as relações existentes (Christofoletti, 1999). Esses modelos podem ser gerados por intermédio de técnicas estatísticas multivariantes, com o intuito da ordenação e classificação dos dados, objetivando uma análise espacial dos mesmos.

Nesse sentido, o uso dessas técnicas permite que se faça uma análise objetiva do fato em estudo, obtendo-se informações subjacentes aos dados utilizados, uma vez que avalia as relações sob um enfoque sistêmico, entre todas variáveis, sem considerar apenas a sobreposição das mesmas.

\section{FUNDAMENTAÇÃO TEÓRICA}

Conforme salientam Silva e Souza (1987), a essência da pesquisa científica é o estudo de relações, levando à criação de estruturas que formalizam as relações do mundo real expressas em dados.

Isso pode ser evidenciado notadamente na Geografia, que trata de questões de caráter predominantemente multivariado, e, portanto compostas das mais complexas relações. Essas relações nem sempre são simples, principalmente considerando o fato de estudá-las no âmbito espacial, de considerável importância na avaliação geográfica.

Racine e Reymond (1973) comentam que o conhecimento geográfico tem como base a comparação e diferenciação de fenômenos que ocorrem sobre a superfície terrestre. Os fenômenos geográficos, assim, resultam da superposição de diferentes tramas humanas de organizações visíveis e invisíveis.

Os autores ainda comentam que as relações resultantes dessa superposição são obtidas a partir de matrizes que contêm um número de momentos perceptivos igual ao produto das 
observações pelos seus atributos, portanto de grandes dimensões e de difícil interpretação.

Sendo assim, o problema da redução e da simplificação das matrizes é fundamental.

Constituída a matriz de informação, o objetivo da geografia consiste em ordenar e simplificar, reaproximando os semelhantes e afastando os dessemelhantes, isto é, agrupar os atributos de mesma distribuição e as observações de mesmas características, de maneira a reduzir a matriz original ao menor número possível de momentos perceptivos, através de diferentes métodos.

Valente (1982) também comenta que a análise espacial através de matrizes redunda em grande volume de dados, e que é de toda conveniência para uma descrição estatística das relações indivíduos/propriedades.

Aos métodos que se referem Racine e Reymond (1973), Valente (1982) e Borouche e Saporta (1982) consideram como de análise de dados, os quais pressupõem que as informações estejam dispostas em matrizes. A aplicação desses métodos conduz a uma redução na dimensão do espaço de partida até uma escala compatível com a interpretação humana, perdendo o mínimo de informação.

Dentre esses métodos, dois grandes tipos podem ser identificados, conforme os objetivos a atingir (VALENTE, 1982):

1 - Métodos de classificação ou de segmentação da população em grupos: cujo objetivo é dividir a população de partida num certo número de grupos com base num critério de "similitude":

Métodos de classificação hierárquica - os indivíduos que são agregados (métodos ascendentes) ou separados (métodos descendentes) ficam desde logo afastados a uma dicotomia que já não pode ser alterada no decurso do processo.

Métodos de classificação não-hierárquica - é necessário dar à priori um número $\mathrm{k}$ de classes em que se pretende segmentar a população I e um conjunto de k "núcleos" para essas classes, o processo consiste em colocar os indivíduos em classes, mudando os núcleos e os indivíduos de cada classe no decorrer do processo.

2 - Métodos de deteç̧ão estrutural ou de visualização: cujo objetivo principal é extrair as estruturas presentes na matriz de dados, sintetizando a informação de base e retendo os aspectos estruturais mais importantes: 
Análise fatorial - termo genérico que descreve uma técnica matemática, cujo objetivo é "explicar" a variabilidade da população de base através de um pequeno número de "fatores" independentes. É importante segundo o ponto de vista probabilístico.

Análise das componentes principais - comparada com a Análise Fatorial, tem um caráter puramente descritivo, baseando-se em conceitos geométricos simples. O objetivo básico é transformar o conjunto inicial das variáveis interdependentes num outro conjunto de variáveis ortogonais (eixos) tal que seja máxima a inércia explicada por cada eixo a extrair sucessivamente.

Análise das correspondências - baseado em tabelas de contingência torna-se original pelo fato de possibilitar a projeção simultânea dos indivíduos e propriedades nos mesmos eixos fatoriais, o que permite retirar conclusões sobre a estrutura de relações entre os dois conjuntos de dados.

A avaliação de relações entre as variáveis de expressão espacial traz à tona quase que instantaneamente a noção de mapa como representação, no plano, de fenômenos geográficos.

O mapa nada mais é do que um modelo de representação gráfica de uma matriz de dados que expressa nas colunas as variáveis (ou atributos), nas linhas os lugares (casos ou observações) e na intercessão de ambas a informação (BERTIN, 1980; MARTINELLI, 1991; ZUQUETTE, 1987).

$\mathrm{Na}$ análise espacial efetuada através de mapas, o número de elementos (unidades, indivíduos ou áreas) e atributos envolvidos é normalmente muito grande, e para tanto, conforme salienta Zuquette (1987), deve ser executada através de matrizes, e desta maneira obtém-se classificações mais corretas.

Ainda segundo Zuquette (1987), pode-se analisar com mais lógica um determinado mapa ao se fazer as análises sobre as matrizes que representem os mapas e cita que Berry (1964) considera que existem pelo menos dez caminhos para a análise dos dados através das matrizes:

1. Estudar o arranjo de células dentro de uma fila ou em parte;

2. Estudar o arranjo de células dentro de uma coluna ou em parte;

3. Realizar comparações entre séries de colunas, tentando buscar diferenças com base em certas características; 
4. Realizar comparações entre séries de colunas, observando covariações especiais ou associações de atributos;

5. Estudar as variações dentro de uma sub-matriz;

6. Comparar uma fila ou parte, através do tempo, ou seja, observar se há mudanças numa área particular através de estágios;

7. Comparar uma coluna ou parte, através do tempo, observando mudanças na distribuição espacial dos atributos;

8. Verificar se houve mudanças na diferenciação das áreas com o tempo;

9. Estudar as mudanças da associação espacial dos atributos em função do tempo; e

10. Realizar estudos comparativos de sub-matrizes através do tempo, por fila e coluna. Cole (1972) salienta que do ponto de vista geográfico, métodos de análise fatorial podem ser considerados como os que comparam vários mapas de uma região em estudo, cada mapa contendo uma distribuição. Nesse intuito, é capaz de processar os dados de maneira imparcial e de produzir resultados relativamente precisos e de forma compacta.

Gould (1967) comenta nessa direção ao afirmar que os profissionais da Geografia estão constantemente trabalhando com mapas. Uma vez que estes são modelos simplificados da realidade, oferecem pouca oportunidade para manipulação das informações diretamente quanto ao entendimento dos fenômenos representados. Há a possibilidade de levantar questões sobre os padrões e estruturas observadas nos mapas e especular sobre o entendimento dos processos espaciais, através da transformação das informações cartográficas em números, capazes de serem manipulados matematicamente.

Chamussy et al. (1980) comentam que a análise multidimensional permite aproximar com vantagens a complexidade das realidades geográficas. Dentre as técnicas utilizadas, consideram a análise fatorial um procedimento sintético e descritivo, que desempenha um papel análogo ao dos mapas de síntese tradicionais, entretanto são menos empíricos. Nesse sentido, a análise fatorial descreve sinteticamente as relações entre estruturas espaciais e estruturas temáticas: este é um dos objetivos essenciais da geografia.

Saadi (1985) salienta então que se a ciência geográfica objetiva a descrição e a classificação de formas resultantes das interações entre vários elementos e processos repartidos no espaço, a análise multivariada apresenta-se como um instrumento adaptado a tal tarefa, que a estatística clássica não pode cumprir totalmente. Afirma ainda que se a ciência geográfica objetiva descobrir as relações entre os diversos elementos básicos para explicar a repartição 
espacial das formas descritas, a análise multivariada atua como "método de redução dos dados", colocando em evidência as dimensões implícitas, expressão das relações internas.

A abordagem multivariada, ainda segundo Saadi (1985), permite destacar tanto as regularidades quanto anomalias, a organização interna dos fenômenos geográficos e consequentemente estabelecer comparações e tipologias, afinal as sínteses e os zoneamentos tão procurados.

Conforme Legendre e Legendre (1998), a identificação das estruturas ecológicas nos dados multidimensionais está baseada na associação de matrizes, onde há muitas variantes, cada qual conduzindo para diferentes resultados (amplos ou restritos) e que até mesmo nos métodos denominados associações-livres, como componente principal, análise de correspondência ou agrupamento tipo k-médias, sempre há uma medida de semelhança implícita no método. Afirmam também, que há dois caminhos abertos para pesquisas ambientais - a análise de agrupamento (aglomerativo, divisivo ou particional) e a ordenação (componente principal ou análise de coordenada, escalonamento multidimensional não métrico ou análise de correspondência), onde o primeiro permite formar grupos semelhantes com os dados multidimensionais e o segundo permite uma ordenação no espaço com a redução do número de dimensões.

A principal vantagem de se utilizar análise multivariada diz respeito às sucessivas aproximações que podem ser feitas sobre o território e as inter-relações espaciais entre elementos que podem ser obtidas em cada caso. Sem o uso dessas técnicas a possibilidade de se incluir ou excluir novas variáveis é muito trabalhoso. Neste sentido, a abordagem incluindo esses tipos de análises é bastante promissora, como demonstram os estudos citados neste item.

Salienta-se que para tal abordagem é necessária a existência de uma área delimitada fisicamente contendo uma base temática de dados consistentes, um SIG e um software estatístico adequados, bem como a definição acertada dos métodos para que sejam efetuadas as análises necessárias.

Segundo Silva (2003), a análise numérica contribui bastante para analisar a complexidade dos dados ambientais, visto que normalmente as variáveis ambientais estão altamente interrelacionadas, excedendo a capacidade dos métodos estatísticos elementares. De maneira geral no estudo do meio ambiente (ecologia), um determinado conjunto de condições ambientais origina diferentes resultados (outcomes), devido ao grande número de variáveis 
ambientais que as influenciam, das quais muitas não são perceptíveis ao observador (LEGENDRE e LEGENDRE, 1998). Nas relações existentes entre as condições que cercam as observações ecológicas e seus resultados é que se encontra fundamentada a análise numérica.

No trabalho de composição de mapas relativos aos aspectos ambientais, Zuquette (1987) afirma que normalmente existe um arranjo dos dados de campo e o estabelecimento de classes, baseadas principalmente em valores quantitativos das propriedades de unidades físicas ou amostras, que formam grupos empíricos, deixando de lado a ordenação em classes abstratas.

De Pablo et al. (1987), trabalhando com cartografia integrada e sua avaliação sob enfoque da teoria da informação, afirmam que para a maior parte das metodologias de descrição integrada do território, a integração dos diferentes aspectos em questão é feita através de indicadores, reconhecidos como a presença ou ausência dos elementos do território.

Esses indicadores permitem exprimir de maneira simplificada a grande quantidade de informações necessárias para elaborar as sínteses integradas do território, podendo ser utilizadas como a base de referência para a cartografia.

Ainda segundo De Pablo et al. (1987), em cartografia ecológica, a escolha de indicadores, é efetuada subjetivamente ou por meio de tratamento numérico de um vasto conjunto de variáveis ecológicas. Dos valores ou intervalos de valores, de uma ampla gama de parâmetros ecológicos, podem coincidir com a presença ou ausência dos indicadores sobre diferentes pontos do território.

A análise multivariada para ser aplicada na cartografia ambiental integrada, com elevado número de unidades espaciais, envolvendo diferentes parâmetros do território, deve possibilitar o uso de variáveis nas escalas nominal e ordinal. Isto é necessário, considerando a impossibilidade de dispor de todas variáveis em escala numérica (intervalar ou de razão). Diante deste fato, as técnicas da Análise de Agrupamento (Cluster Analysis) e a Análise Fatorial das Correspondências - AFC se mostram apropriadas ao procedimento. A combinação de ambas é também uma opção, quando se utiliza a Análise de Agrupamento em seguida à $A F C$.

No que diz respeito aos métodos de classificação, Landim (1995) comenta que a aplicação dos mesmos é controversa, uma vez que pouco se sabe a respeito de suas propriedades estatísticas, e apenas testes limitados são conhecidos para verificar a significância dos 
resultados. Segundo Borouche e Saporta (1982), os métodos de classificação ou de tipologia têm por objetivo agrupar os indivíduos em um número restrito de classes homogêneas.

Uma forma de averiguar o ajuste das matrizes é visualmente, num sistema de eixos ortogonais, onde a reta diagonal indica o ajuste perfeito e o desvio dela indica a existência dos coeficientes de similaridade mais altos, seja em relação a um dendrograma ou aos originais.

Utilizando o procedimento de classificação da análise de agrupamento, Pablo et al. (1987), procuraram expressar cartograficamente as interações espaciais, como subsídio a planificação do território, utilizando variáveis biológicas e fisiográficas da província de Madrid (Espanha). O trabalho procurou avaliar o poder sintético e integrador dos mapas, assim como o valor cartográfico das variáveis indicadoras.

As variáveis foram registradas segundo sua presença ou ausência, em 675 parcelas de $1 \mathrm{~km}^{2}$. Foram avaliados três procedimentos de classificação, considerando diferentes sequências de avaliação das variáveis, seja envolvendo todas de uma vez ou iniciando por grupo temático até chegar a considerar todas as variáveis. O resultado pôde ser verificado pelas diferentes combinações cartográficas obtidas. A tônica do processo de integração está na busca de uma visão global, sem considerar os temas individualmente e sem fazer suposições a priori sobre os parâmetros que podem exercer influência na diferenciação dos setores ecológicos.

A capacidade sintética de cada carta gerada no trabalho pôde ser avaliada no que diz respeito a sua capacidade de estimar suas propriedades como canal de informação, através de uma análise da entropia. Os resultados demonstraram que:

$\checkmark$ - O procedimento é útil para selecionar a carta que tem a melhor distribuição de um grupo de variáveis especialmente pertinentes para a cartografia;

$\checkmark$ - A informação mútua entre muitas cartas permite induzir outras novas que resumem a informação mais significativa;

$\checkmark$ - O procedimento utilizado permite reconhecer em diferentes escalas, as variáveis indicadoras e integradoras da informação ecológica, colocando em evidência aquelas que possuem o melhor valor de síntese. Essas variáveis podem ser empregadas para elaborar uma nova cartografia ou para planificar as prospecções mais detalhadas.

Utilizando o mesmo procedimento da análise de agrupamento, Lima et al. (1996), procuraram avaliar o mapeamento da morfodinâmica de parte da bacia do rio Mogi 
(Cubatão-SP), buscando comparar o resultado obtido por Castro (1993), através do uso de sistema de informação geográfica, e de CETESB (1991) através de método convencional. Foram utilizadas 25 variáveis no total, e considerada a presença ou ausência das mesmas em células com dimensões de 350 × 350 m. Os dados foram coletados segundo dois métodos distintos:

$\checkmark$ - O primeiro deles considerando a variável dominante em termos de área, e nesse caso só haveria uma variável por célula;

$\checkmark$ - No segundo caso considerando em cada célula a existência da variável com área de ocorrência superior a 30\% da área da célula, possibilitando que houvesse a existência em uma mesma célula de uma ou mais variáveis.

Utilizou-se no trabalho o coeficiente de similaridade "Simple Matching"- SM, e o método de agrupamento "Unweigthed pair-group method arithmetic averages" - UPGMA.

Para efeito comparativo visual, os resultados obtidos no trabalho demonstraram um bom resultado, considerando a resolução espacial utilizada $(350$ × 350 m) e levando em consideração o fato, também considerado no trabalho de Pablo et al. (1987), relativo ao não privilégio de uma variável sobre outra, mas buscando-se o efeito integrador do método.

No que diz respeito ao método de coleta de dados, o que permitiu a presença de mais de uma variável por célula apresentou melhor resultado, inclusive quanto ao coeficiente de correlação cofenético. Este resultado mostrou-se bastante interessante pelo fato de diferir da tradicional forma de representação de dados utilizada nos SIG's e pode se constituir em opção de tratamento de dados multidimensionais.

Quanto à análise fatorial das correspondências, esta técnica foi desenvolvida por Benzécri (1976, 1992), com base nos dois tipos fundamentais de análise fatorial: Análise das Componentes Principais e Análise Canônica.

As propriedades matemáticas do método são apresentadas, sucintamente, com base em Carr (1990), que por sua vez se baseou em Benzécri (1976). Sendo assim, salienta que a técnica é desenvolvida com base em uma tabela de contingência, a partir da qual a geometria das linhas (indivíduos) é relacionada à geometria das colunas (atributos) resultando em uma correspondência entre linhas e colunas, conferindo à técnica um qualificativo de geométrica, porém baseada estatisticamente. 
A técnica proporciona uma noção geométrica de correlação, ou sela, como indivíduos e atributos se agrupam. Em cada gráfico são identificadas associações: atributo-atributo, indivíduo-indivíduo e atributo-indivíduo.

Landim (1995), a respeito disso, comenta que diferentemente de técnicas multidimensionais como a análise das componentes principais e a análise fatorial, na análise das correspondências os autovalores são extraídos a partir de tabelas de contingência e não de correlações, onde os valores originais são transformados de modo a poderem ser interpretados como possibilidades condicionais. Sendo assim, por causa dessas transformações as relações entre colunas e linhas da tabela transformada são as mesmas que aquelas da matriz original de dados, significando que as soluções para o modo $Q$ e para o modo $\mathrm{R}$ são equivalentes e desse modo, o produto final mostra num espaço bidimensional, definido pelos dois mais importantes autovetores, a distribuição simultânea tanto das amostras como das variáveis.

Segundo Saadi (1985), a vantagem da análise fatorial das correspondências em relação a outras técnicas multidimensionais reside no fato de que não necessita de dados numéricos, por vezes de difícil disponibilidade, e repartição normal, possibilitando fornecer ligações não-lineares entre caracteres descritivos, algo importante, haja vista que esse tipo de ligação é regra geral do meio ambiente".

Além disso, abre possibilidade de trabalhar no estudo das relações entre variáveis de diferentes tipos e origens, sejam das ciências físicas, naturais e biológicas e/ou das humanas, sociais e econômicas.

Ainda segundo Saadi (1985), entre outras propriedades particulares, a A.F.C. tem a de possibilitar o tratamento simultâneo de "dados principais" (caracteres ativos) e de "dados suplementares" (caracteres passivos). Os primeiros intervêm diretamente na determinação dos eixos fatoriais, enquanto os outros só aparecem na representação gráfica, sendo as suas localizações no espaço definidas pelas proximidades existentes com os dados principais. Essa propriedade é rica de aplicações ao estudo da dinâmica ambiental.

A literatura disponível sobre o uso da A.F.C. aplicada a estudos sobre a análise espacial do meio físico, ainda é escassa. Saadi (1985) cita algumas aplicações interessantes nos campos da tipologia e estrutura das paisagens e da cartografia ambiental, incluindo também a possibilidade de utilização em estudos de erosão dos solos. 
Saadi (1985) salienta que a A.F.C. pode ser considerada como suporte logístico á análise ambiental, possibilitando o alcance de objetivos tanto de descrição como de explicação e classificação, além do que, utilizada cuidadosamente tem condição de ajudar no que se refere ao enfoque previsional.

Quanto ao aspecto cartográfico, de interesse particular neste trabalho, Saadi (1985) também destaca a importância dessa técnica, graças às seguintes propriedades: tratamento simétrico dos espaços dos indivíduos e dos caracteres com representação gráfica simultânea; propriedade baricêntrica e interpretação em função da proximidade que reduz a semelhança. Além disso, o fato de todos os pontos estarem localizados por coordenadas numéricas em um espaço de três dimensões permite inclusive um mapeamento direto das unidades homogêneas com base em programas de cartografia automática.

Thomassin (1985) utilizou-se da A.F.C. e da classificação ascendente hierárquica para elaborar representação cartográfica sobre as condições físicas e potencialidades da Serra Equatoriana, com o objetivo de comparar com a delimitação de zonas agrícolas homogêneas desenvolvidas pela ORSTOM. Utilizou 26 variáveis relativas ao meio físico e suas potencialidades, oriundas de documentos cartográficos analíticos, os quais foram rasterizados, gerando uma malha de 7200 linhas por 3840 colunas. As informações foram homogeneizadas com relação à menor unidade administrativa considerada no país, perfazendo um total de 348 unidades locacionais. As variáveis receberam notas de 0 a 10 conforme a intensidade do fenômeno considerado e dessa forma foram ordenadas em modalidades. A tabela principal foi construída com 238 linhas e 95 colunas, representando as modalidades das 26 variáveis e da intercessão das linhas e colunas foi definida a presença (1) ou ausência (0) da informação.

Com isso foi submetida à A.F.C. e em seguida à classificação ascendente hierárquica sobre o conjunto das unidades administrativas. A autora conclui que a partir de dados provenientes de inventários do meio físico, ecológico e humano, tentou-se realizar a síntese, sem deixar que nada fosse perdido referente à ordem e a relação dos dados. As representações cartográficas, estabelecidas a partir dos fatores fundamentais que estruturam a realidade geográfica, propõe sobre a Serra Equatoriana uma imagem acessível de uma certa originalidade, mostra que a análise de dados é para o geógrafo prudente, uma ferramenta eficaz e de uso relativamente fácil. 
Brossard (1980) realizou trabalho na região de Spitsberg (Ártico), procurando avaliar o espaço de uma maneira global (por integração de elementos variados do sistema paisagem) e de uma maneira experimental (por cartografias "encadeadas"). Procurou dar relevância aos aspectos da abordagem espacial e proposições de soluções práticas. Nesse sentido, os dados obtidos através de uma malha de quadrículas permitiram varrer muitos níveis de escala e determinar por análises encadeadas os limites remarcáveis da organização da paisagem, como a vegetação (presença e abundância das espécies), que é tomada como indicador no estudo. $\mathrm{O}$ autor salienta que a análise multivariada permite estabelecer uma classificação tipológica. Os gráficos restituem um espaço orientado onde as distâncias entre os elementos de análise se definem segundo a coesão lógica do conjunto. A essas distâncias gráficas podem ser conciliadas significações variadas.

Sendo assim, o tratamento estatístico é efetuado através da A.F.C. e da classificação hierárquica. O procedimento adotado permitiu passar muito rápido à cartografia, pois cada indivíduo é diretamente classificado.

Os dados são objeto de partições sucessivas: cada conjunto se divide em dois subconjuntos e assim por diante. Foram elaboradas, então, quatro cartas em diferentes níveis de classificação. O autor conclui que com o procedimento adotado não há possibilidade de abandonar ou privilegiar nenhum setor em estudo, em função da hipótese de pesquisa, porque a observação sistemática dá essa garantia. Não é negligenciada a avaliação clássica do terreno, mas ela se aplica sobre um espaço metodicamente avaliado. Nesse sentido, o autor evidencia que a análise sistemática é indispensável para a geografia, que é eficaz em realçar a estrutura dos objetos que ela estuda ou de perceber como é sua dinâmica. Estes métodos modernos de tratamento da informação permitem ao geógrafo definir modelos cada vez mais complexos, avaliar modalidades de variações espaciais e ter o recurso à cartografia experimental.

Wieber (1980), em trabalho desenvolvido na temática cartografia das paisagens e análise dos sistemas produtores, estudou as combinações dos elementos constitutivos da paisagem como um sistema de forças, procurando fazer uma reflexão na linha de estudos globais em geografia física. Um dos procedimentos do trabalho foi o recurso aos métodos de classificação tipológica baseados sobre o tratamento estatístico e da informática, os quais permitem o reagrupamento de indivíduos idênticos ou semelhantes, descritos pelos dados múltiplos, constituindo em importantes recursos na resolução de problemas geográficos. Os 
dados do trabalho foram obtidos através de uma malha de triângulos equiláteros, totalizando 5, 100 pontos, referentes a uma área de aproximadamente $1.500 \mathrm{~km} 2$. Para cada ponto amostral foram definidos 89 caracteres possíveis. Estes foram submetidos à A.F.C. e em seguida à classificação hierárquica ascendente para os caracteres, que possibilitou a obtenção de 28 tipos determinados nos eixos fatoriais. Cada ponto do espaço (indivíduo) está associado a um dos tipos obtidos, cuja simbologia adotada permite a passagem para a cartografia. $\mathrm{O}$ trabalho resultou em um modelo tipológico que pode ser aplicado na área sob estudo e até extrapolado para áreas semelhantes.

Silva (2003) desenvolveu estudo de planejamento ambiental no Mato Grosso, e procurou fazer uma comparação de um método tradicional e do uso da AFC para o zoneamento ambiental. Ao final da pesquisa, o autor fez as seguintes considerações:

$\checkmark$ - A aplicação da análise multivariada integrando informações biofísicas e socioeconômicas, associada a um Sistema de Informações Geográficas de fácil manejo e baixo custo permite aprimorar a execução de diagnósticos e identificação de unidades de zoneamento, que pode auxiliar na tomada de decisão em planejamento ambiental;

$\checkmark$ - Essa estratégia metodológica é essencialmente quantitativa e de fácil repetição, garantida pela robustez do método estatístico, cujas etapas de análise são claramente explicitadas.

A análise multivariada, de uma forma geral, suscita reflexões, como sugere Saadi (1985), tanto para a Geografia como para outras ciências. Algumas dessas reflexões dizem respeito aos seguintes pontos:

$\checkmark$ - constitui-se em abordagem mais rigorosa e coerente: uma vez que costumeiramente se trabalha com dados de diferentes unidades, regra geral procede-se a homogeneização de forma mais rigorosa do que na prática geográfica clássica;

$\checkmark$ - é uma análise mais exaustiva e objetiva: todo fato espacial é considerado de interesse, sem restrição, cabendo à técnica realizar a triagem e facilitar a escolha dos mais representativos, chegando-se a uma análise mais objetiva pela neutralidade da técnica;

- representa um avanço conceitual para a geografia física: passa-se do estudo monográfico ao estudo de estruturas latentes e à concepção de modelos 
reprodutíveis, que permitem a classificação, a generalização e as comparações, utilizando-se de descritores ou variáveis não necessariamente ligados à ciência de interesse;

$\checkmark$ - há uma complementaridade no caso da geografia física, entre a geografia naturalista e a quantitativa: o uso da análise multivariada precisa ser precedido de um bom conhecimento naturalista, necessário à boa escolha das variáveis.

\section{MATERIAL E MÉTODOS}

\section{Área de estudo}

A área sob estudo encontra-se na porção oriental do Estado da Paraíba, mais precisamente na mesorregião do litoral paraibano. Ocupa uma área na qual os tabuleiros costeiros se estendem para o interior do Estado, e, portanto, encontra-se no limite ocidental da zona fisiográfica do litoral/mata. Foi selecionada porque sobre a mesma já haviam sido obtidos dados de alguns fatores da EUPS, sobretudo de erodibilidade e erosividade. Os valores de erodibilidade, de um lado, serviriam como referência para comparações com os dados obtidos com o método indireto, e de outro, poderiam ser utilizados caso houvesse algum problema com as medidas indiretas ou com a análise geoestatística.

Situa-se aproximadamente entre os meridianos de $35^{\circ} 08^{\prime} 16^{\prime \prime}$ e $35^{\circ} 15^{\prime \prime} 12^{\prime \prime}$ de longitude a oeste de Greenwich e os paralelos de $06^{\circ} 59^{\prime} 18^{\prime \prime}$ e $07^{\circ} 05^{\prime} 42^{\prime \prime}$ de latitude sul (Figura 1 ).

Segundo a classificação de Köppen a área em estudo enquadra-se regionalmente no subtipo climático As', com as seguintes características: amplitude térmica inferior a $50 \mathrm{C}$, temperatura média anual entre $22^{\circ} \mathrm{C}$ e $26 \circ \mathrm{C}$, com os meses de janeiro e fevereiro sendo os mais quentes do ano e os de julho e agosto, os de temperatura mais amena. A precipitação pluviométrica média anual é de aproximadamente $900 \mathrm{~mm}$, com os meses de junho e julho apresentando os maiores índices pluviométricos do ano. O período de estiagem é de 5 a 6 meses, estendendo-se de setembro/outubro a janeiro/fevereiro, sendo o mês de novembro o mais seco.

Segundo a classificação climática de Gaussen, a área sob estudo encontra-se nos domínios da modalidade climática 3dth - submediterrâneo (Mediterrâneo quente e subseco), pertencendo à grande região climática "Xerotérica-Mediterrânea", sendo mais conhecida no Brasil como "Nordestina". 
As características dessa modalidade climática são: estação seca de 1 a 4 meses, curva térmica sempre positiva e temperatura do mês mais frio sempre superior a 15ㅇ C. O índice xerotérmico varia de 0 a 40 e o maior índice de precipitação pluviométrica é tipicamente de inverno. Sob esse domínio climático encontram-se formações vegetais de floresta de médio e alto portes, formações de transição floresta subcaducifólia-cerrado e áreas tipicamente de formação de cerrado.

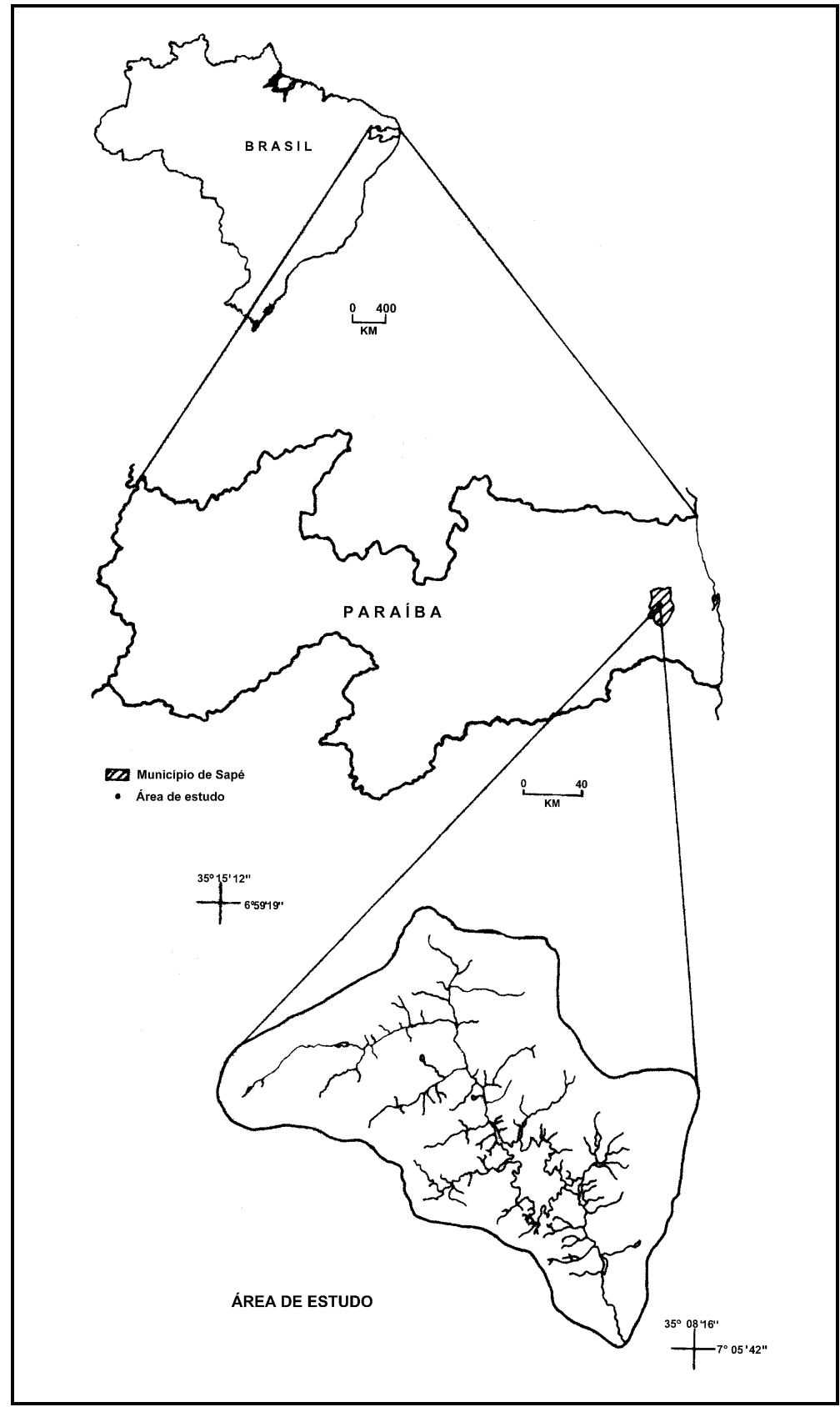

Figura 1 - Mapa de localização da área de estudo 
Com base nos dados de precipitação pluviométrica do período de 1961 a 1991, do posto meteorológico da cidade de Sapé, a mais próxima da área de estudo, foi elaborado o gráfico a seguir. Segundo esses dados, a precipitação média anual foi de $891,53 \mathrm{~mm}$.

A área em estudo está inserida no domínio morfológico do Baixo Planalto Costeiro, e como está numa área de transição com a Depressão Sublitorânea, encontra-se dissecada por rios que demandam o Atlântico, deixando aflorar o cristalino nos vales abertos e pouco profundos, como é o caso do vale do principal rio, o Una, que corta a área no sentido nortesul.

Quanto à altimetria, as maiores cotas ocorrem associadas aos Baixos Planaltos Costeiros, variando de 130 a 200m, nas porções oeste e leste da área, e as menores na porção central associada aos terrenos da Depressão Sublitorânea, com altitudes que variam de 30 a $80 \mathrm{~m}$.

Os Baixos Planaltos Costeiros, modelado nos sedimentos do Grupo Barreiras, constituem-se em uma superfície sub-estrutural semi-tabular, com mergulho na direção NE-E, que se estendem no sentido norte-sul por todo o litoral do Estado da Paraíba, alcançando até 60 $\mathrm{Km}$ no sentido leste-oeste e possui terrenos pouco elevados (variando de 30/40 metros próximo ao mar, até 200 metros no limite ocidental, onde está localizada a área de estudo) (Carvalho, 1982). Tem superfície plana, e, em alguns casos, em colinas residuais de topos semi-aplainados, muitas vezes de constituição arenosa. Ocorrem na área em estudo, bem preservados, nas suas porções oriental e ocidental, em toda extensão norte-sul, constituindo-se nos interflúvios do vale do riacho Una.

No rebordo dos vales existentes na área, o relevo apresenta-se ondulado, com vertentes íngremes e nos talvegues há o afloramento do cristalino. Os afluentes do riacho Una, que cortam a área no sentido leste-oeste, apresentam vales mais fechados, constituindo-se numa fase mais recente da dissecação dos Baixos Planaltos Costeiros.

Associados aos Baixos Planaltos Costeiros estão sedimentos do terciário, representados por coluna estratigráfica predominantemente plano-paralela e constituída de material pouco consolidado areno-argiloso, muitas vezes intercalados com leitos de seixos de quartzo rolado e concreções lateríticas, pertencentes ao Grupo Barreiras do Plioceno (SAMPAIO, 1973). Esses sedimentos podem apresentar espessuras superiores a $50 \mathrm{~m}$; entretanto, na área em estudo, a espessura varia de 10 a 30 m, uma vez que se trata de uma área próxima à zona de transição sedimento-cristalino, e, portanto, o capeamento sedimentar é menos espesso. 
A superfície da Depressão Sublitorânea apresenta-se como uma planície semi-colinosa, de topos semi-arredondados e vertentes em geral convexas, com altitudes variando de menos de $80 \mathrm{~m}$ nos fundos de alguns vales até 100-130 m (CARVALHO, 1982). Ocorre na Paraíba entre o Maciço da Borborema e o Baixo Planalto Costeiro, em toda extensão norte-sul do Estado, resultante de um processo de exumação do cristalino pela retirada da cobertura detrítica terciária do Grupo Barreiras (CARVALHO, 1982). Na área de estudo em particular, a superfície da Depressão Sublitorânea constitui uma reentrância dos Baixos Planaltos Costeiros no sentido norte-sul, resultado da ação erosiva do riacho Una, afluente do rio Paraíba. Essa feição ocorre num trecho em que os Baixos Planaltos apresentam, no Estado da Paraíba, a maior extensão no sentido leste-oeste.

Nos vales de maior expressão, correspondendo à superfície da Depressão Sublitorânea, ocorrem rochas do pré-cambriano, relativas ao embasamento cristalino exumado, representadas por gnaisses e migmatitos associados ao granito. No vale do riacho Una, principal curso da microbacia, a jusante do açude Pacatuba, e, portanto, no trecho inferior do mesmo, ocorrem sedimentos recentes do quaternário - holoceno. Estes se referem exclusivamente aos aluviões e Solos Hidromórficos na área. Compõem-se de camadas de areia não consolidada ou da alternância destas com outras, de constituição argilosa ou argilo-siltosa, podendo ocorrer ainda depósitos orgânicos semidecompostos (SAMPAIO, 1973).

Embora já bastante devastadas, as formações vegetais na área de estudo apresentam testemunhos da ocorrência de floresta subcaducifólia, floresta caducifólia, cerrados e campos de várzea.

A floresta subcaducifólia ocorre em parte dos tabuleiros costeiros, nos terrenos menos arenosos e nas vertentes mais úmidas dos mesmos, formando conjuntos mais ou menos densos de espécimes retilíneos, com altura variando em torno de 15 a 20 metros, parte dos quais perde a folhagem na estação seca. A mais importante ocorrência dessa formação vegetal na área encontra-se na vertente leste do vale do riacho Una, nas proximidades do açude Pacatuba, constituindo uma reserva particular, na qual estão as nascentes de alguns córregos afluentes do riacho Una. Esta formação vegetal ocorre na zona de transição entre as modalidades bioclimáticas 3dTh - Mediterrâneo quente e subseco de Litoral/Mata e o 3cTh - Mediterrâneo quente ou Nordestino de seca atenuada da zona do Agreste ou Caatinga Litorânea. As espécies mais freqüentes são (Sampaio, 1973): Pau-d'arco-amarelo 
(Tabebuia chrysotricha); louro (Ocotea spp); embirindiba (Buchenavia capilata); jatobá (Hymenaea spp); catolé (Syagrus oleracea Bicc.), entre outras.

A floresta caducifólia ocorre nos terrenos cristalinos de parte de alguns vales da área, no domínio morfológico dos terrenos suavemente ondulados a ondulados, caracterizando-se por espécies arbóreas, muito ramificadas e esparsas, com um substrato arbustivo quase que totalmente constituído de marmeleiros. A característica dessa formação vegetal está na sua perda total de folhas durante o período de estiagem. Apresenta característica de transição para a caatinga hipoxerófila e está subordinada às condições do bioclima 3cTh Mediterrâneo quente ou Nordestino de seca atenuada. As principais ocorrências dessa formação são no vale do riacho Una, constituindo verdadeiros resquícios florestais em meio a grandes áreas de campos antrópicos destinados à pastagem. Suas principais espécies são: braúna (Schinopsis brasilenses); juazeiro (Zyziphus Joazeiro); mulungu (Erithrina velutina); aroeira (Astronium urundeuva Engl.); catingueira (Caesalpinia pyramidalis); angico (Anadenanthera macrocarpa (Benth)); canafístula (Cassia excelsa Schrad); marmeleiro (Crotton sp); mandacaru (Cereus jamacaru).

Os cerrados são associações vegetais que ocorrem em grandes áreas contínuas ou alternadas com formações florestais, e em estreita correlação com solos arenosos ácidos e pobres em nutrientes, permitindo o surgimento de uma vegetação pouco exigente. Compõem-se de espécies arbóreo-arbustivas de pequena altura, com troncos tortuosos, casca suberosa e fendilhada, com galhos baixos e irregulares, formando agrupamentos pouco densos e muitas vezes esparsos com um substrato predominantemente constituído de gramíneas. Ocorrem principalmente na porção leste da área, nas proximidades da reserva de floresta subcaducifólia do Pacatuba, sobre os tabuleiros, estando associados a solos bastante arenosos. As espécies arbóreas e arbustivas de maior ocorrência são: murici-detabuleiro (Byrsonima cydoniaefolia); lixeira ou cajueiro brabo (Curatella americana L.); batiputá (Ouratea fieldingiana); mangaba (Hancornia speciosa) e cajueiro (Anacardium occidentale L.).

Os campos de várzea ocorrem nas baixadas alagadas e nas margens dos riachos Una e Parede, e são compostos por formações rasteiras e gramíneas, associadas a terrenos pouco drenados e sujeitos a inundação. As espécies características dessas formações são: Panicum virgatum (Gramineae); Cyperus giganteus (Ciperaceae); Montrichardia sp (Araceae) e Acrosticum sp (Polypodiaceae). 
O uso da área é destinado predominantemente à cultura da cana-de-açúcar, nos terrenos planos dos tabuleiros costeiros, mas ocupando também terrenos dos vales, se estendendo sobre as vertentes dos baixos planaltos. Associados à cana-de-açúcar, desta feita ocupando principalmente os fundos de vale com terrenos do pré-cambriano e solos menos espessos, estão os campos antrópicos destinados à pastagem. Ocorrem ainda dispersos, pequenos sítios com ocorrência de culturas temporárias, tais como mandioca, milho, feijão, e árvores frutíferas, destinados à subsistência de famílias, geralmente ocupadas na cultura da cana-deaçúcar. No vale do riacho Parede encontra-se uma área não muito extensa ocupada com a cultura do coco.

Os solos que ocorrem na área podem ser subdivididos em dois grupos que estão associados ao material de origem. Portanto, sobre os terrenos dos sedimentos do terciário encontramse solos com horizonte B textural e argila de atividade baixa, assim como solos com horizonte B podzol e areno-quartzosos. Sobre os terrenos do pré-cambriano encontram-se solos com horizonte $B$ textural e argila de atividade alta e solos pouco desenvolvidos dos fundos de vale.

Os solos existentes sobre os terrenos planos dos sedimentos terciários e sobre as vertentes, na transição sedimento-cristalino, são, basicamente: Argissolo Vermelho-Amarelo, Neossolo Quartzarênico e Espodossolo Hidromórfico.

Os solos que ocorrem associados aos terrenos cristalinos dos vales, são: Luvissolo, Neossolo Litólico e Neossolo Aluvial.

\section{Procedimentos}

Os procedimentos adotados na pesquisa estão relacionados com a aquisição de dados referentes aos parâmetros da EUPS (Equação Universal de Perdas de Solo) (WISHMEIER E SMITH, 1978), quais sejam, erodibilidade do solo (K), erosividade da chuva (R), comprimento de vertente (L), declividade (S), cobertura vegetal e uso do solo (C), e práticas conservacionistas $(\mathrm{P})$.

Levando em consideração as pequenas dimensões da área de estudo $(73,44 \mathrm{~km} 2)$, o parâmetro erosividade da chuva (R) foi considerado constante na mesma, haja vista não haver nítida variabilidade espacial, uma vez que é um fator que está relacionado com as precipitações pluviométricas. 
No que diz respeito ao parâmetro práticas conservacionistas $(P)$, foi também utilizado um valor constante para toda área de estudo, adotando-se o valor de 0,5 , relativo ao plantio em contorno (cuja escala cobre o intervalo de 0,0 a 1,0) (BERTONI E LOMBARDI NETO, 1993), considerando que essa seja uma prática de conservação adotada em um contexto de exploração agrícola tecnificada (Pinto, 1991) na realidade do Estado da Paraíba. Isto ocorre tendo em vista a área ser explorada por usinas, destilarias e fornecedores de cana e esses exercerem influência sobre os demais produtores no que diz respeito às práticas agrícolas e de conservação adotadas.

A adoção de um valor que seria considerado médio em termos de perdas de solo relativas às práticas de conservação é justificada pelo fato de que se torna difícil identificar com precisão quais seriam as técnicas utilizadas por propriedades agrícolas. Este tipo de informação não seria facilmente obtido através de produtos de sensoriamento remoto aéreo ou orbital. Além disso, leva-se em consideração que em uma pequena área não deve haver variações consideráveis quanto às práticas conservacionistas, em virtude da cultura agrícola existente e dos recursos técnicos disponíveis numa mesma realidade sócio-econômica.

A espacialização dos parâmetros da EUPS foi feita conforme Pinto (1991), coletando-se dados pontuais utilizando uma grade regular com quadrículas de dimensões de $0,5 \times 0,5 \mathrm{~cm}$, sobreposta a cartas topográficas e mapas temáticos na escala de 1:25.000. Para ajuste da grade regular aos documentos cartográficos foi utilizada a malha de quadrículas UTM. De acordo com o sistema de coleta de dados, foram geradas grades com 4478 quadrículas para cada parâmetro da EUPS.

Depois de gerados os dados referentes aos parâmetros da EUPS, os mesmos foram inseridos em sistema computacional (Sistema de Informação Geográfica) no formato de representação matricial (raster), que é apropriado para aplicação do modelo, por meio da integração dos fatores da equação devidamente espacializados.

A construção da base digital de dados espaciais, constituída pelos parâmetros da EUPS, poderia ser feita por meio da conversão, no próprio sistema, de arquivos de dados no formato vetorial (mapas digitalizados) para o formato matricial. Entretanto, o procedimento tradicional de coleta e inserção de dados no sistema computacional adotado neste trabalho, que é normalmente utilizado em trabalhos que aplicam o modelo EUPS (PINTO, 1991; VALENZUELA ET AL, 1986; CHRISMAN ET AL., 1986), justifica-se pelo controle sobre os mesmos. 


\section{Fator erodibilidade do solo}

O fator erodibilidade do solo da EUPS é um parâmetro que exprime a suscetibilidade do solo à erosão laminar, obtido originalmente em experimentos desenvolvidos em parcelas experimentais no campo. Varia conforme as características físicas e químicas dos solos, que se modificam de acordo com o tipo de solo.

É normalmente definida para unidades de solo, nas quais se desenvolvem experimentos em parcelas experimentais para determinação direta ("in loco") da erodibilidade do solo. Nesse sentido necessita-se fazer medidas de perdas de solo em função da ocorrência de chuvas, que demanda considerável soma de tempo, recursos e condições técnicas para tal.

Alternativamente a esse procedimento, desenvolveram-se técnicas de obtenção indireta da erodibilidade do solo, a partir do fato de que algumas características físicas e químicas dos solos que foram utilizados para determinação direta da erodibilidade, se correlacionavam muito bem com o resultado do parâmetro obtido no campo. A partir dessa constatação, pesquisas começaram a ser desenvolvidas em várias unidades de solo e em determinadas condições ambientais, no sentido de encontrar características físicas e químicas dos solos, de fácil determinação em laboratório e/ou em campo, que pudessem reproduzir o parâmetro de erodibilidade do solo utilizado na EUPS.

A determinação indireta da erodibilidade vem sendo adotada em diversos tipos de solo e em várias regiões do Brasil e do mundo, entretanto, o parâmetro é determinado, a exemplo do que ocorre com o procedimento direto, para unidades inteiras de solo, teoricamente homogêneas, em função das normas e técnicas de classificação dos mesmos.

As unidades de solo, entretanto, apresentam heterogeneidade interna quanto algumas características físicas e químicas, principalmente nos horizontes superficiais, que mais influência tem nos processos erosivos laminares. Com relação a isso, pesquisas vêm sendo desenvolvidas (WEBSTER, 1985; YATES E WARRICK, 1987; LOAGUE E GANDER, 1990) para estudar a variabilidade espacial dos solos no que diz respeito a várias características e aplicações.

No que concerne ao parâmetro erodibilidade de solos para uso na EUPS, vários métodos de determinação indireta da erodibilidade têm sido desenvolvidos: Dumas (1965), Wishmeier, Johnson e Cross (1971), Roth, Nelson e Römkens (1974), Lombardi Neto e Bertoni (1975), El- 
Swaify e Dangler (1977), Römkens, Roth e Nelson (1977), Lima (1987), Paez (1989), Lima et al. (1990), Denardin (1990), Cavalieri (1994) e Chaves (1994)). No presente trabalho foi adotado o modelo proposto por Chaves (1994), a partir de dados da região do vale do rio São Francisco, por se tratar de dados de uma realidade geográfica mais próxima da encontrada na área de estudo, bem como pela utilização de parâmetros de fácil determinação.

O modelo utilizado de Chaves (1994) foi o seguinte:

\section{$K=2,47 \times 10^{-3}(\mathrm{SIL})-5,23 \times 10^{-3}(\mathrm{OAL})+8,89 \times 10^{-3}(\mathrm{CO}) 2+1,5 \times 10^{-2}(\mathrm{OFE})-1+1,42 \times 10^{-4}(\mathrm{OSI}+$ OSI2) $-1,89 \times 10^{-2}[\mathrm{OSI} /($ OFE + OAL) $] 2$

onde: $\mathrm{SIL}=$ teor de silte do solo; $\mathrm{OAL}=$ óxido de alumínio extraído por ácido sulfúrico; $\mathrm{CO}=$ teor de carbono orgânico; OFE = teor de óxido de ferro extraído por ácido sulfúrico; OSI = teor de óxido de silício extraído por ácido sulfúrico (todos dados em porcentagem).

As análises físicas de solo referentes ao modelo utilizado foram realizadas no laboratório do Departamento de Solos e Engenharia Rural do Centro de Ciências Agrárias da Universidade Federal da Paraíba, localizado na cidade de Areia/PB. As análises químicas foram realizadas no laboratório do Centro Nacional de Pesquisas de Solo (CNPS/EMBRAPA) localizado na cidade do Rio de Janeiro.

Inicialmente havia sido definido que seriam coletadas amostras de solo nas profundidades de $0-10 \mathrm{~cm}, 10-20 \mathrm{~cm}$ e $20-30 \mathrm{~cm}$, para avaliação da variabilidade tanto no sentido horizontal como vertical; entretanto, pelas primeiras amostras obtidas, observou-se que demandaria muito tempo para coleta do material e ficou definido que as coletas passariam a ser feitas na profundidade de $0-20 \mathrm{~cm}$.

A idéia inicial era a de que as amostras seriam coletadas para avaliação da variabilidade espacial interna a cada unidade de solo identificada em mapa de solos disponível (1:80.000), e, conseqüentemente, para toda a área de estudo; entretanto a técnica das variáveis regionalizadas (geoestatística) utilizada no estudo da variabilidade espacial exige que sejam utilizados mais de 30 dados para obtenção de resultados confiáveis. Sendo assim, não foi possível obter o número de amostras necessárias para algumas unidades de solo devido às dificuldades de acesso e também porque algumas delas ocorriam em áreas muito restritas, o que provocaria o menor espaçamento entre amostras em alguns locais e o maior 
espaçamento em outros, independentemente das dificuldades de acesso. No total foram obtidas 276 amostras de solo em toda a área de estudo.

Assim sendo, as amostras foram obtidas sem levar em consideração necessariamente a quantidade por unidade de solo, mas procurando-se estabelecer, na medida do possível, um determinado espaçamento entre as mesmas e uma representação da posição na topografia local, ou seja, procurando-se obter amostras nas porções inferior, média e superior das vertentes. De qualquer forma, foram obtidos alguns parâmetros de estatística descritiva das amostras em algumas unidades de solo para efeito de comparação.

Essa forma de obtenção das amostras foi definida levando-se em consideração que os dados de solos referenciados na literatura estão sempre dispostos por unidades de solo. Por outro lado, para análise da variabilidade espacial de propriedades de solo por meio da geoestatística, Moore et al. (1993) comentam que não é levada em consideração a pedogênese, ou seja, não se considera necessariamente as unidades de solo para obtenção de dados.

Coletadas as amostras, foram feitas as determinações exigidas pelo modelo de Chaves (1994), utilizando métodos analíticos descritos por Brasil (1979). No caso da análise granulométrica, para determinação do teor de silte, foi utilizado $\mathrm{NaOH} \mathrm{0,1} \mathrm{mol} \mathrm{L-1} \mathrm{como}$ dispersante.

Os valores de erodibilidade obtidos em laboratório foram submetidos à análise com métodos de estatística clássica, calculando-se a média, variância, desvio padrão, coeficiente de variação, mínimo, máximo, amplitude, assimetria e curtose. Também foi feita uma análise da distribuição de freqüência dos dados, para avaliar se os mesmos seguiam distribuição normal ou log-normal. O tratamento estatístico foi feito por intermédio do programa EXCEL. Em seguida, os dados foram submetidos à análise de dependência espacial por meio do uso de semivariogramas. O ajuste de modelos aos semivariogramas para definição de seus parâmetros (efeito pepita, alcance e patamar), foi feito pelo processo de tentativa e erro. Após a avaliação da dependência espacial foi efetuada a interpolação por krigagem. O mapa de isovalores de erodibilidade foi impresso na escala de 1:25.000 e sobre o mesmo foi sobreposta à grade regular de quadrículas com dimensões de $0,5 \times 0,5 \mathrm{~cm}$. A malha de quadrículas foi inserida no programa IDRISI, via teclado, gerando-se o plano de informações erodibilidade.

Todo tratamento geoestatístico foi realizado com o programa SPRING/INPE. 


\section{Fator erosividade da chuva}

A erosividade da chuva, como mencionado anteriormente, foi definida como sendo constante em toda a área de estudo.

Foi gerado um plano de informação de erosividade, no IDRISI, utilizando os mesmos parâmetros espaciais do plano de informação erodibilidade e para toda a área foi utilizado um único valor.

\section{Fator topográfico}

O fator topográfico da EUPS consiste do comprimento da vertente (L) e da declividade (S) (WISHMEIER E SMITH, 1978). Para obtenção do mesmo foram gerados os fatores comprimento da vertente e declividade, utilizando-se para isso carta topográfica na escala 1:25.000, folhas Sapé e Capim.

Inicialmente, as curvas de nível foram extraídas das cartas topográficas para um papel poliéster e definidas as linhas que definem divisores de água em locais que são limitados por uma mesma curva de nível. Em seguida, a grade regular foi sobreposta às curvas de nível e medidas as distâncias entre o limite topograficamente inferior da grade e a cota de maior valor a montante nas vertentes, procurando identificar o sentido do escoamento preferencial das águas pluviais, perpendicularmente às isolinhas, pelo comportamento da topografia local, conforme utilizado em Pinto (1983), Pinto (1991) e IPT (1986). Considerouse como a cota de maior valor na vertente, quando não definida claramente por um divisor de águas, o local onde ocorre mudança no sentido de escoamento das águas em função de alguma saliência na topografia, mesmo ocorrendo no terço médio de uma vertente, uma vez que nesse caso haveria alteração na velocidade do fluxo superficial das águas e, a partir daquele ponto, é que haveria a retomada da velocidade do fluxo.

Cada quadrícula da grade assumiu um valor de distância em relação ao ponto inicial de deslocamento do fluxo de água, expressando o comprimento do percurso realizado pelo fluxo. Quanto maior o comprimento, maior a velocidade do fluxo e, em conseqüência, maior o poder erosivo das águas superficiais. 
Utilizando as mesmas referências espaciais dos planos de informações gerados anteriormente, os valores de comprimento da vertente foram inseridos no IDRISI, via teclado, para gerar o plano de informação de mesmo nome.

Para obtenção da informação espacial da declividade foi utilizado papel poliéster com a definição das isolinhas. Sobre o mesmo foram utilizados dois métodos de obtenção da declividade, propostos por De Biasi $(1970,1992)$ e Sanchez (1993). Segundo o método de De Biasi (1970, 1992), a declividade é obtida utilizando-se ábaco triangular que é deslocado entre as curvas de nível com cotas diferentes da carta topográfica. O método de Sanchez (1993) considera que em áreas de topo e em vales, que são limitados por curvas de nível de mesmo valor, deve-se usar, para determinar a mesma declividade encontrada pelo método de De Biasi, a metade da dimensão usada nesse ábaco, considerando como pontos de referência o curso do rio, no caso dos vales, e uma linha que define uma crista, no caso dos topos. Para ambos os casos foram definidas as seguintes classes de declividade: $<2 \%, 2$ a $5 \%, 5$ a $10 \%, 10$ a $20 \%, 20$ a $40 \%$ e > $40 \%$.

Construído o mapa com as facetas que apresentam áreas de uma mesma classe de declividade, foi sobreposta ao mesmo a grade regular e definido para cada quadrícula o limite superior da classe de declividade coincidente com o centro da quadrícula. Obtida a malha com os valores de declividade, foram utilizadas as referências espaciais dos planos de informação já existentes e inseridos os valores no IDRISI, via teclado, constituindo um plano de informação de declividade.

A partir dos dados espacializados em meio digital de comprimento das vertentes (L) e declividade (S), o fator topográfico foi obtido aplicando-se a formulação proposta por Bertoni (1959) e apresentada por Bertoni e Lombardi Neto (1993):

$$
L S=0,00984 \cdot L^{0,63} \cdot S^{1,18}
$$

\section{Fator cobertura vegetal}

O fator cobertura vegetal (C) da EUPS (WISHMEIER E SMITH, 1978) foi gerado a partir da interpretação de fotografias aéreas na escala aproximada de 1:40.000, obtidas em 1985. 0 uso dessas fotografias foi suficiente para a elaboração do mapa pretendido, porque se 
observou nos diversos trabalhos de campo realizados, que não tinha havido alteração significativa nos tipos de cobertura vegetal e de uso do solo existentes na época de tomada das mesmas.

As alterações ocorridas e percebidas foram devidamente realizadas e se referiram à ampliação ou retração de áreas de cana-de-açúcar ou pasto, de padrões facilmente identificáveis nas fotografias aéreas.

A partir da fotointerpretação realizada foi gerado um overlay que em seguida foi ajustado à escala de 1:25.000, utilizando-se, como referência, o quadriculado do sistema UTM (Fuso 25).

A cada classe de uso do solo existente na área de estudo foi atribuído um valor de C, definido em diversos trabalhos (PINTO, 1991; LEPRUN, 1981; LEPRUN E SILVA, 1994; BERTONI E LOMBARDI NETO, 1993), e, portanto, obtido na literatura.

Sobre o mapa de uso do solo e cobertura vegetal gerado, foi sobreposta a grade regular e para cada classe de uso e cobertura vegetal predominante em cada quadrícula foi atribuído o valor de C correspondente. Com isso foi constituída uma nova matriz de dados que foi inserida no IDRISI, via teclado, gerando-se o plano de informação referente ao fator $\mathrm{C}$ da EUPS. Para isso foram utilizados os planos de informação já existentes como parâmetros espaciais para sua geração.

\section{Integração dos dados}

Conforme os objetivos do trabalho, a integração dos dados se deu de duas formas distintas, visando uma comparação entre ambos, com o intuito de avaliar diferentes técnicas de análise espacial disponíveis em sistemas computacionais.

Em ambos os casos o intuito foi de avaliar a intensidade relativa do potencial de erosão laminar dos solos, bem como sua distribuição espacial, sem necessariamente haver preocupação com a quantificação das perdas de solo. Nesse sentido, a contribuição do modelo preditivo utilizado foi a de fornecer os parâmetros envolvidos no estudo do fenômeno, assim como valores referenciais de cada fator, oriundos de pesquisas conduzidas por um longo intervalo de tempo.

O primeiro procedimento é de ampla utilização na integração de grandes conjuntos de dados espaciais, assim como na aplicação de modelos matemáticos com variáveis 
ambientais que tenham abrangência espacial (VENTURA ET AL., 1988; VALENZUELA, 1988; PINTO, 1991; FERREIRA, 1995; CASTRO E VALÉRIO FILHO, 1997; LIMA, 1990; FORMAGGIO ET AL., 1992; CASTRO, 1993).

O procedimento consiste de uma aplicação básica dos sistemas de informação geográfica que corresponde à sobreposição de vários níveis de informação espacial referentes a uma mesma área. Em se tratando da integração de matrizes de dados espaciais multivariados, essas matrizes têm que ter o mesmo número de linhas e colunas e as células homólogas das matrizes possuem a mesma referência espacial, ou seja, a mesma localização no espaço.

A regra seguida para a integração dos planos de informação foi a aplicação do modelo EUPS (Equação Universal de Perdas de Solo, A = R.K.L.S.C.P), utilizando as seguintes informações espaciais (mapas):

$\checkmark$ Erosividade da chuva (R);

$\checkmark$ Erodibilidade do solo (K);

$\checkmark$ Declividade (S);

$\checkmark$ Comprimento de vertente (L);

$\checkmark$ Cobertura vegetal (C);

$\checkmark$ Práticas conservacionistas (P).

Para obtenção do resultado final, representado pela informação espacial do potencial de erosão, foram adotados procedimentos intermediários que constituem a geração de subprodutos referentes à aplicação de alguns fatores do modelo.

O primeiro procedimento intermediário na aplicação da formulação foi a obtenção de um fator relativo às variáveis topográficas do modelo, declividade e comprimento de vertentes. Assim sendo, foi obtido um plano de informação denominado de fator topográfico, utilizando-se a seguinte formulação (BERTONI, 1959; BERTONI E LOMBARDI NETO, 1993):

$L S=\left(0,00984 L^{0,63} \cdot S^{1,18}\right)$

onde: L é o comprimento de vertente e S é a declividade.

O segundo procedimento intermediário adotado foi a geração de um fator que exprime potencial natural de erosão, envolvendo os fatores do modelo referentes apenas às variáveis do meio físico. Nesse caso foi gerado um plano de informação denominado de Potencial Natural de Erosão (PNE), utilizando-se a seguinte formulação: 
O resultado final da aplicação do modelo EUPS foi obtido por intermédio do produto dos planos de informação, Potencial Natural de Erosão (PNE), Cobertura Vegetal (C) e Práticas Conservacionistas $(P)$, sendo gerado o plano de informação denominado de Perdas Relativas por Erosão do Solo (PR).

O segundo procedimento adotado para integração dos dados foi a aplicação da análise fatorial das correspondências. Este procedimento consiste de uma técnica estatística multivariada classificatória, desenvolvida com base em uma tabela de contingência, a partir da qual a geometria das linhas (indivíduos) é relacionada à geometria das colunas (atributos ou variáveis) resultando em uma correspondência entre linhas e colunas. Assim sendo, os fatores do modelo EUPS foram considerados como variáveis (atributos) e as localizações no espaço das mesmas foram consideradas como casos (indivíduos), para a construção da matriz de entrada. O desafio da aplicação dessa técnica foi o de que a utilização de um grande conjunto de dados pudesse permitir a obtenção de um resultado que pudesse ser espacializado, vindo a constituir um mapa. Esse mapa poderia ser classificado em áreas de potencial relativo de erosão do solo.

O procedimento foi adotado e o resultado foi comparado com o mapa final obtido com o da aplicação do modelo EUPS. A comparação foi feita utilizando-se a técnica da tabulação cruzada, disponível no programa IDRISI.

O procedimento foi utilizado com o objetivo de se obter um resultado de expressão espacial, sem ter que utilizar um modelo pré-concebido.

\section{RESULTADOS}

\section{Obtenção das informações espaciais referentes aos parâmetros da EUPS}

São descritos os resultados encontrados na obtenção da informação espacial (mapas) dos fatores da EUPS, erodibilidade, erosividade, declividade, comprimento de vertente, uso e cobertura do solo e práticas conservacionistas, que integrados permitem avaliar o potencial de erosão da área sob estudo. 


\section{Erodibilidade}

Considerando que o modelo utilizado para determinação indireta da erodibilidade leva em consideração parâmetros físicos e químicos dos solos, os resultados obtidos corroboram com o encontrado na literatura a respeito da variabilidade espacial dos solos.

A informação espacial mostra que a maior parte da área de estudo possui baixos valores de erodibilidade (entre 0.0007 e 0.04 ) e essas áreas se distribuem por todas as unidades de solo existentes, mas concentram-se naqueles que ocorrem nos tabuleiros costeiros, onde ocorrem solos mais arenosos. Ocorrem em diferentes posições na topografia, nas áreas planas dos topos dos tabuleiros, nas vertentes e no fundo dos vales.

As áreas de maior erodibilidade também ocorrem em diferentes unidades de solo, mas concentram-se nos Argilossolos, Luvissolos e Neossolos Aluviais, principalmente em áreas de vertentes e no fundo do principal e maior vale da área de estudo.

No geral, verifica-se que não há associação entre as áreas de maior ou menor erodibilidade com uma determinada unidade de solo. Nesse caso, ocorre o que Moore et al. (1993) comentam, de que a análise geoestatística de propriedades do solo não leva em consideração a pedogênese. O resultado da espacialização da erodibilidade pode ser visto na Figura 2.

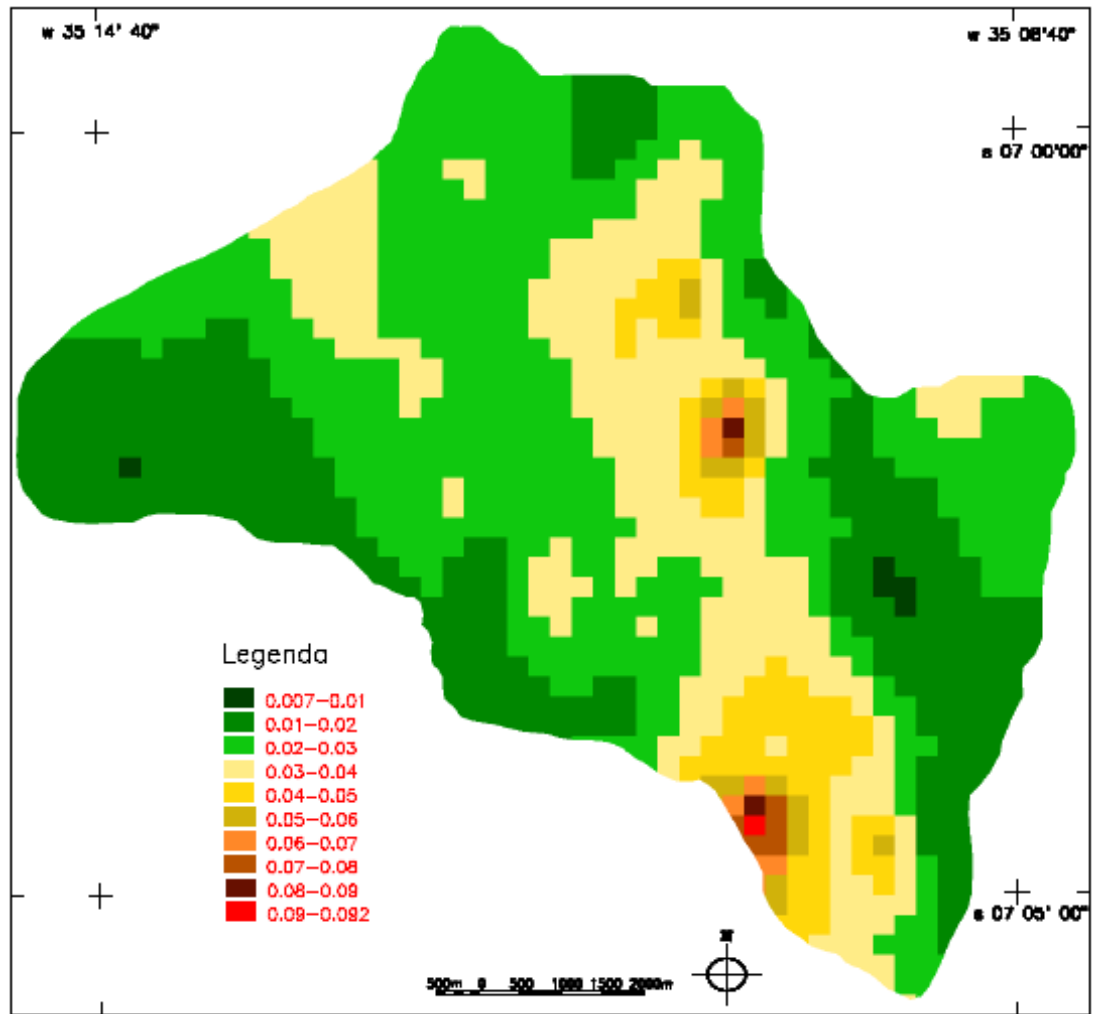

Figura 2 - Mapa de erodibilidade. 
Obtenção dos demais parâmetros da Equação Universal de Perdas de Solo (EUPS) necessários para geração do potencial natural de erosão

\section{Erosividade}

Considerando a pequena dimensão da área de estudo (aproximadamente $73,4 \mathrm{~km}^{2}$ ), foi adotado um único valor de erosividade (Fator R da EUPS) para toda a área, calculado pelo Departamento de Solos e Engenharia Rural da Universidade Federal da Paraíba (Campus de Areia), a partir de dados de precipitação coletados no posto pluviométrico da cidade de Sapé, como sendo o mais próximo da área de estudo. Portanto, o mapa assumiu apenas uma classe, referente ao valor de 3744,59 MJ.mm/ha.h.

\section{Fator topográfico}

O fator topográfico (LS), que é composto pelos parâmetros extensão de vertentes (L) e declividade (S), representa a variável relevo no modelo EUPS (Pinto, 1991). Ambos os dados foram obtidos a partir de carta topográfica na escala de 1:25.000, utilizando -se malha com quadrículas de 0,5 x 0,5 cm, representando uma área de $125 \times 125 \mathrm{~m}$ no terreno.

No que diz respeito aos dados de extensão das vertentes, observou-se, como se pode verificar na Figura 49, uma grande variabilidade nas dimensões das vertentes, com valores de 125 metros até 2375 metros. Entretanto, o predomínio é de vertentes com dimensões de até 500 metros, nas áreas referentes à depressão sublitorânea devido à ocorrência de relevo dissecado em colinas. A ocorrência de vertentes tão extensas, embora em locais restritos, se deve ao fato da existência, na área de estudo, das encostas dos baixos planaltos costeiros no contato com a depressão sublitorânea. Nessas áreas encontram-se extensas encostas suavizadas.

Os dados de extensão de vertentes foram inseridos no sistema de informação geográfica por meio da digitação dos valores, célula por célula.

Quanto aos dados de declividade, pode-se observar sua representação espacial na Figura 4. O mapa mostra a predominância de baixos valores de declividade $(<2 \%$ e $2-5 \%$ ), que ocorrem nos topos dos baixos planaltos costeiros e no fundo do vale do rio Una. Nas encostas são encontrados maiores valores de declividade, com predominância das classes de 
5-10 \%, 10-20 \% e 20-40\%. As áreas com declividade > $40 \%$ são bastante restritas, com maior ocorrência na vertente esquerda do vale do riacho Una, que, pelo comportamento da topografia observado na Figura 22 (curvas de nível), apresenta de fato, mais forte inclinação em função do maior encaixamento da drenagem.

Da mesma forma que os dados da extensão das vertentes, os da declividade foram inseridos no sistema de informação geográfica por meio da digitação dos valores célula por célula. No caso da declividade, como informação que está representada em classes, da mesma forma que a erodibilidade, os valores considerados para cada célula, para efeito da integração dos dados, foi sempre o maior valor da classe.

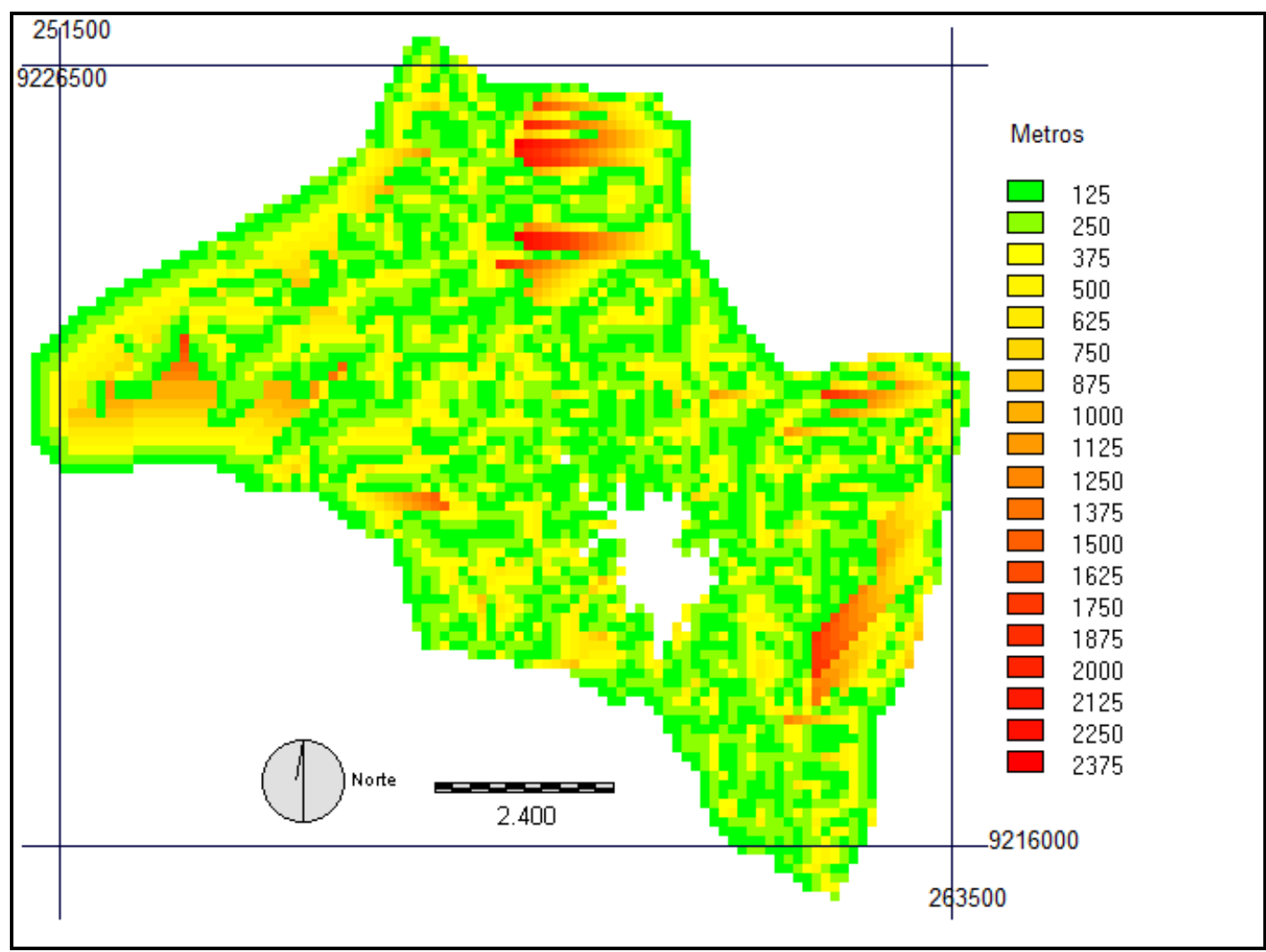

Figura 3 - Mapa de extensão das vertentes. 


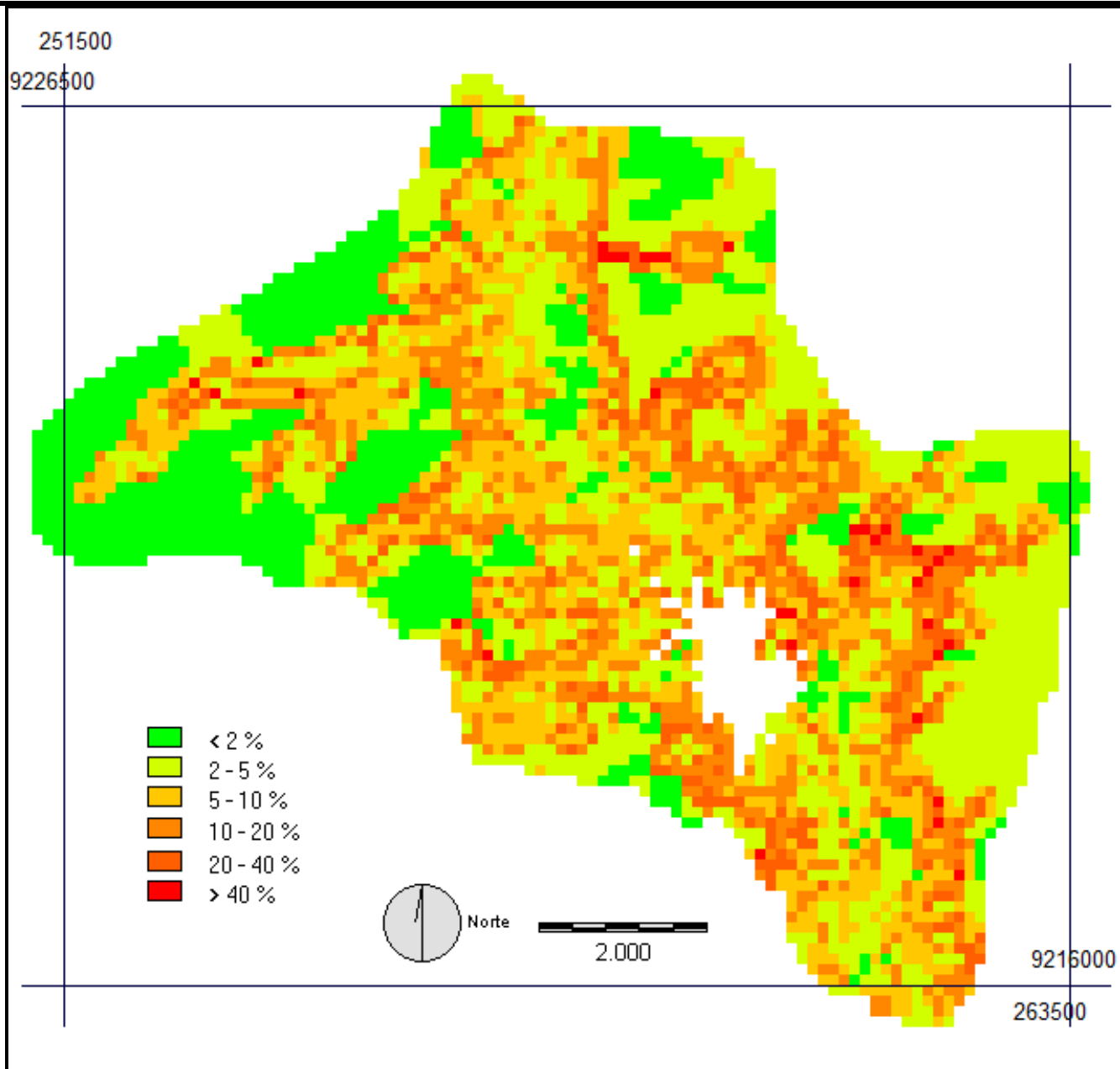

Figura 4 - Mapa de declividade.

Integração dos parâmetros da Equação Universal de Perdas de Solo (EUPS) para determinação do Potencial Natural de Erosão (PNE)

Os planos de informação referentes aos dados do meio físico existentes na EUPS, quais sejam, erosividade (fator R), erodibilidade (fator K) e declividade e extensão das vertentes (fator topográfico - LS), foram integrados no programa IDRISI para geração do potencial natural de erosão (PNE). A integração das informações supracitadas segue a lógica da Equação Universal de Perdas de Solo (EUPS), sendo os fatores multiplicados entre si.

De acordo com os dados da distribuição de freqüência, os valores do potencial natural de erosão apresentam-se baixos (média 391,64 e desvio padrão 931,56), e, por conseguinte, há uma tendência de que a área sob estudo tenha fraca suscetibilidade natural à erosão.

Os valores do plano de informação PNE foram submetidos a um agrupamento em quatro classes, como forma de categorização qualitativa e informal (IPT, 1986; PINTO, 1991), com 
base na análise da distribuição de freqüência e da informação espacial da matriz de dados por intermédio do monitor de vídeo, cujo resultado pode ser observado na Tabela 1.

Tabela 1 - Classes de valores de Potencial Natural de Erosão (PNE).

\begin{tabular}{|c|c|c|}
\hline CLASSES & VALORES DE PNE & $\begin{array}{c}\text { CATEGORIZAÇÃO } \\
\text { QUALITATIVA }\end{array}$ \\
\hline 1 & $1-199$ & Fraco \\
\hline 2 & $200-499$ & Moderado \\
\hline 3 & $500-1499$ & Moderado a Forte \\
\hline 4 & $1500-14817$ & Forte \\
\hline
\end{tabular}

A classificação do plano de informação PNE gerou o mapa de classes de PNE (Figura 4). Realizando uma comparação estritamente visual desse mapa com os de erodibilidade, extensão de vertentes e declividade, observa-se, de um modo geral, que o arranjo espacial das classes de PNE tem uma maior associação com a distribuição espacial das classes de declividade, seguido pela extensão de vertentes, e, por último, pela erodibilidade. No caso específico das áreas de maior potencial natural de erosão verifica-se certa associação com as classes de declividade, assim como com as áreas de maior erodibilidade. Nas áreas de menor potencial erosivo, por sua vez, a associação é maior com as classes de declividade.

Para uma melhor caracterização das relações existentes entre os planos de informação envolvidos na geração do potencial natural de erosão e o mapa de classes de PNE, os sistemas de informação geográfica, de uma forma geral, e o IDRISI em particular, possibilitam a execução de operações estatísticas necessárias para tal. Nesse sentido, foi executada, no IDRISI, a operação estatística de regressão linear, para avaliar a correlação simples existente entre os planos de informação PNE e erodibilidade, PNE e extensão de vertentes e PNE e declividade. Em todos os casos, a variável dependente é o PNE e a variável independente, os parâmetros da EUPS. Para aplicação da regressão linear com cada um dos parâmetros da EUPS, o plano de informação PNE foi constituído de três formas diferentes, considerando os intervalos de classe adotados. No primeiro caso, foi adotado o valor máximo de cada classe como representativo da mesma, no segundo, o valor central, e, no terceiro, o valor mínimo.

Diante dos resultados obtidos com a análise estatística, porém, verificou-se que as maiores contribuições para a constituição das classes de PNE são a erodibilidade e a extensão das vertentes. A declividade, por sua vez, tem o menor percentual de contribuição. Esse resultado difere da percepção visual anteriormente comentada, de que a declividade teria 
maior contribuição para o arranjo espacial das classes de PNE. Em função disso, ressalta-se a importância dos sistemas de informação geográfica como recurso para análise da informação espacial.

Com base nos resultados obtidos, utilizando os dados originais de PNE, observa-se uma maior semelhança dos mesmos com os dados apresentados pela classificação, adotando-se o valor máximo de cada classe como representativo das mesmas. Assim sendo, a maior correlação ocorre com os valores de erodibilidade $(0,5025)$, que explica $25,25 \%$ do PNE, e, em segundo lugar, com a extensão de vertentes (0,3294), que explica $10,85 \%$ dos dados de PNE. Praticamente inexiste relação entre PNE e declividade $(0,0629)$, uma vez que esse parâmetro explica apenas $0,4 \%$ do PNE. Esse fato ocorre considerando que o potencial de erosão é maior ou menor, independentemente de ser a declividade, respectivamente, mais forte ou mais fraca. Nesse caso, valores altos de PNE ocorrem tanto associados a valores baixos como a valores altos de declividade. A declividade não é, necessariamente, o parâmetro de maior importância para o potencial natural de erosão na área de estudo, mas sim a extensão das vertentes. Ocorre que áreas de maior declividade não estão necessariamente associadas a vertentes mais extensas, pelo contrário, algumas vertentes são longas e suaves, e esse fato demonstra ter mais importância para a constituição do potencial natural de erosão. Além disso, deve-se ressaltar a restrita existência de áreas de maior declividade. 


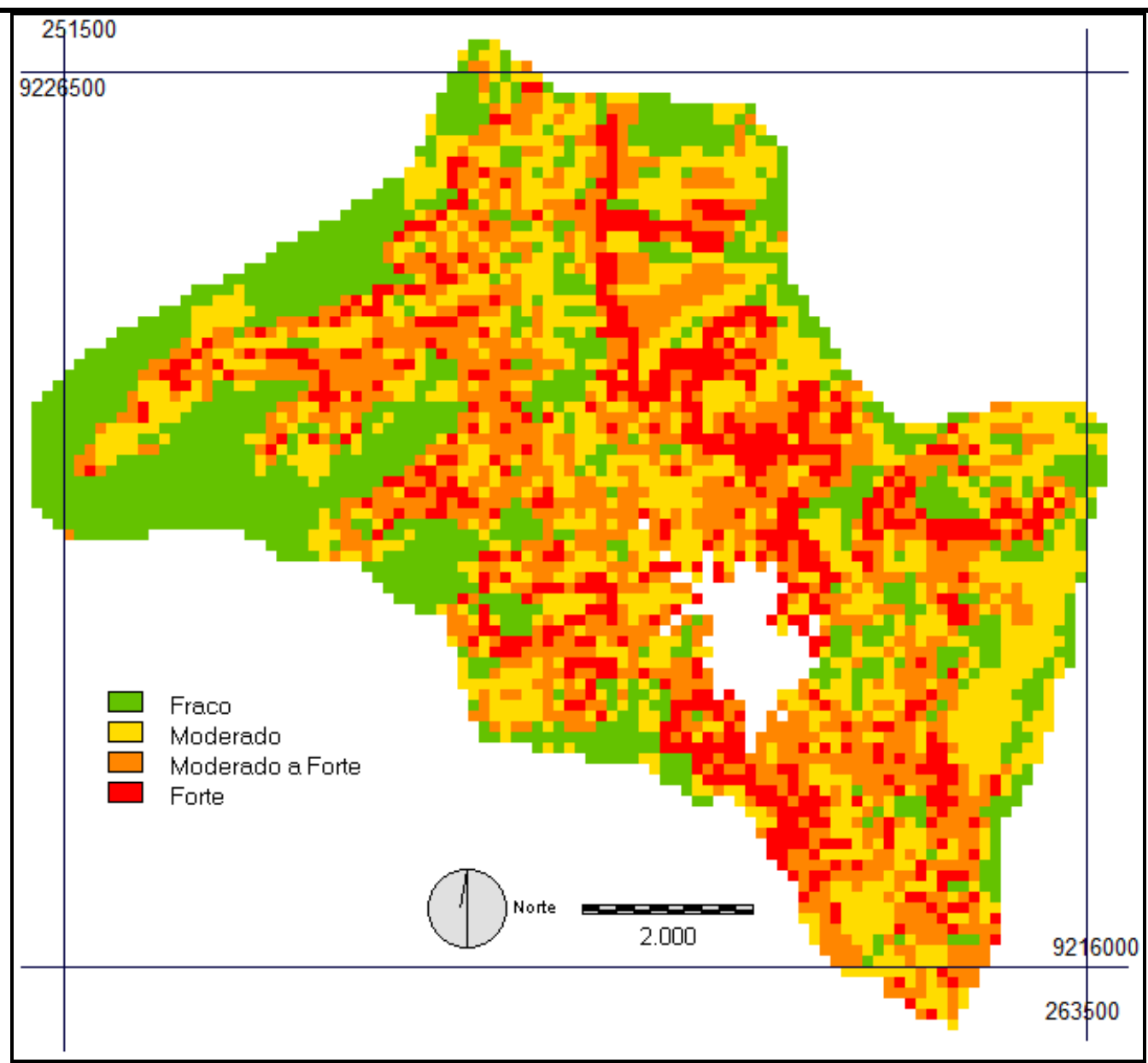

Figura 5 - Mapa de classes de Potencial Natural de Erosão (PNE).

\section{Determinação das perdas relativas por erosão do solo}

Para determinação das perdas relativas por erosão do solo, prosseguiu-se na integração dos parâmetros da Equação Universal de Perdas de Solo, desta feita, utilizando-se o plano de informação PNE, gerado anteriormente, referente aos parâmetros da EUPS relacionados ao meio físico e aos planos de informação de uso da terra $(C)$ e práticas conservacionistas $(P)$. Vale salientar que o procedimento de integração adotado nessa etapa, a exemplo do que foi feito para a geração do plano de informação $\mathrm{PNE}$, também é realizado por meio da multiplicação dos planos de informação, seguindo a lógica da EUPS.

O plano de informação de uso da terra (Figura 6) foi gerado utilizando-se os valores do fator C, conforme exposto na Tabela 2. 


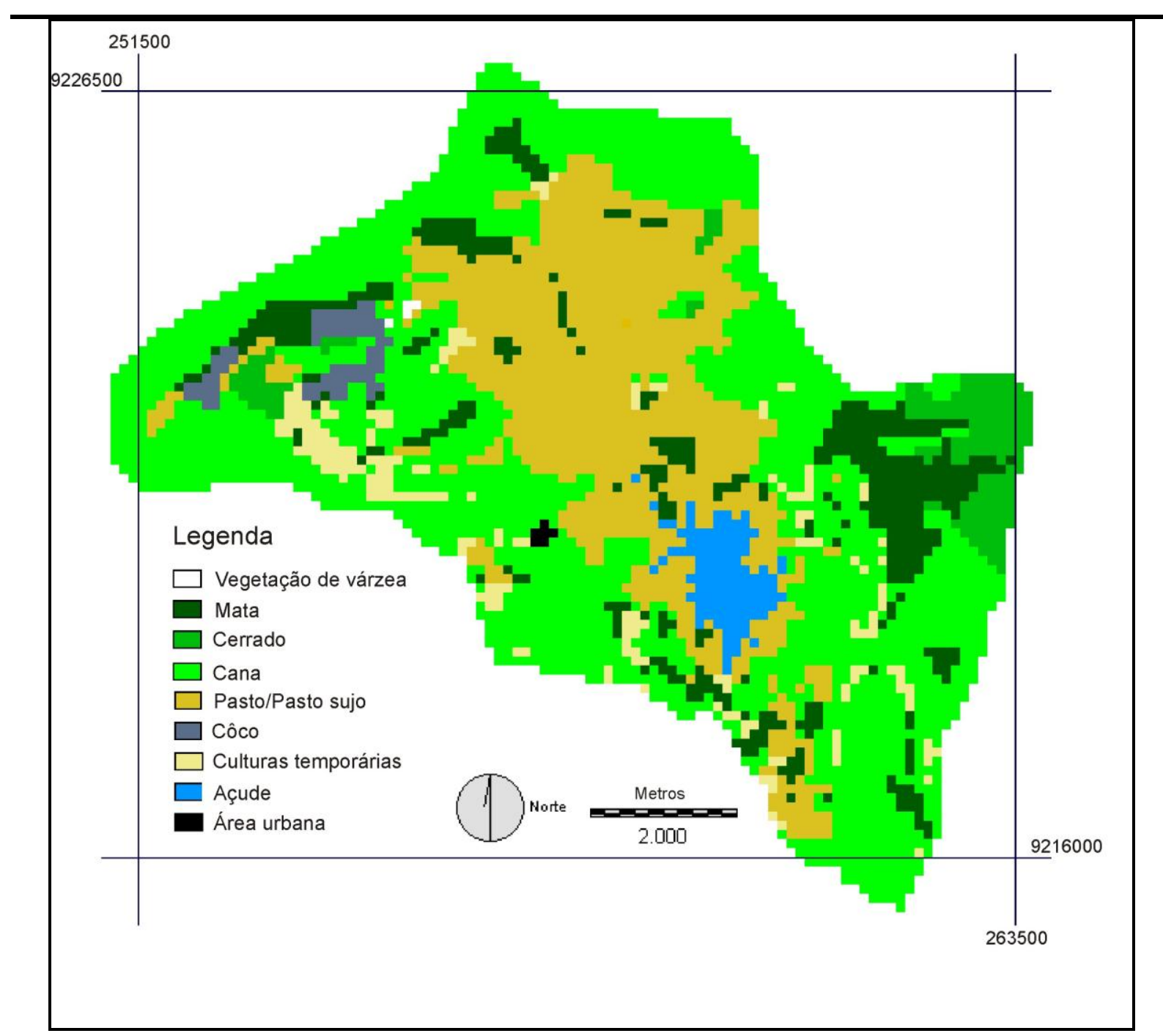

Figura 6 - Mapa de uso da terra/cobertura vegetal (Fator C da EUPS).

Tabela 2 - Valores do Fator $C$ da EUPS relacionados com as categorias de uso da terra da área de estudo.

\begin{tabular}{|c|c|}
\hline USO DA TERRA & VALORES DO FATOR C \\
\hline Culturas Temporárias & 0,21 \\
\hline Cana & 0,004 \\
\hline Pasto & 0,01 \\
\hline Cerrado & 0,0007 \\
\hline Vegetação de Várzea & 0,00 \\
\hline Mata & 0,00004 \\
\hline Côco & 0,02 \\
\hline Residencial & 0,007 \\
\hline
\end{tabular}

A integração do plano de informação PNE com o plano de informação de uso da terra gerou um plano de informação intermediário, denominado de PNC. O plano de informação PNC, por sua vez, foi integrado com o plano de informação práticas conservacionistas (P), que foi constituído com um único valor de 0,5 , em função de se ter considerado genericamente a existência de um mínimo de prática agrícola de conservação. 
Como produto final do modelo EUPS, foi obtido o plano de informação denominado de Perdas relativas por erosão do solo (PR). Com base no histograma desse produto, foi feita uma classificação dos valores (Tabela 3) e gerado um plano de informação das classes de PR

(Figura 7). Da mesma forma que ocorreu com o plano de informação de PNE, ocorre uma grande quantidade de valores 0 (zero), pelo fato de a área de estudo ser irregular e fora dela, assim como no açude localizado em seu interior, todos os valores serem nulos. No caso do plano de informação de PR, além das áreas citadas, as células referentes à vegetação de várzea também apresentam valor nulo, ocorrendo com a cor branca.

Tabela 3 - Classes de Perdas relativas por erosão do solo (PR).

\begin{tabular}{|c|c|}
\hline CLASSES & VALORES DE PR \\
\hline 1 & $0,0001-0,5$ \\
\hline 2 & $0,51-3,0$ \\
\hline 3 & $3,0-10,0$ \\
\hline 4 & $10,1-683,0$ \\
\hline
\end{tabular}

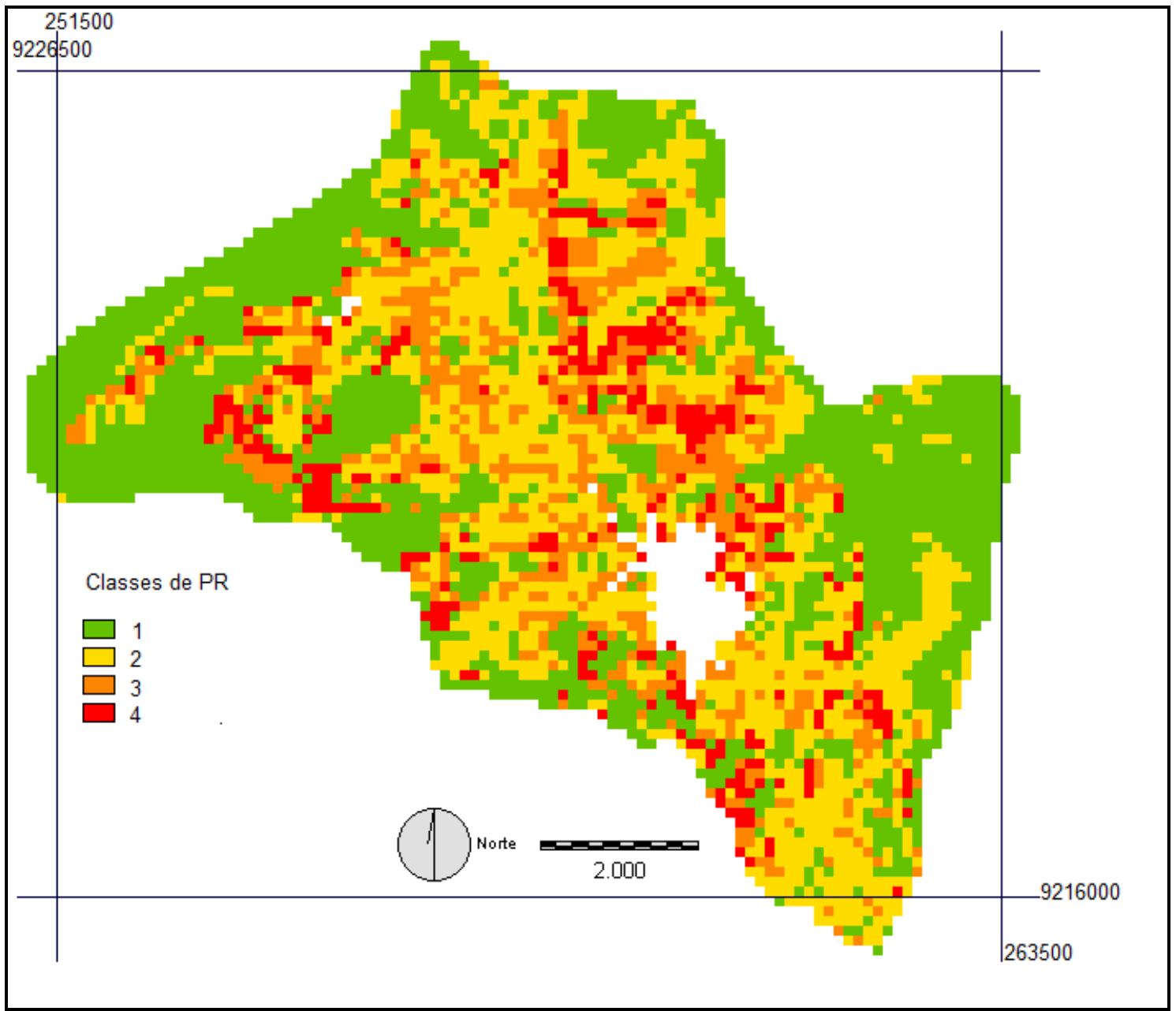

Figura 7 - Mapa das classes de Perdas relativas por erosão do solo (PR) 
A análise visual dos planos de informação de PNE e PR permite identificar que há uma atenuação das expectativas de erosão na área de estudo, em função dos tipos de uso existentes em relação ao potencial erosivo delineado pelos aspectos do meio físico.

Existe uma forte associação com relação às áreas de fraco potencial erosivo e perdas relativas por erosão. Isso se deve ao fato de que, onde ocorre fraca suscetibilidade à erosão, também ocorre uma cobertura vegetal que exerce uma boa proteção do solo, que é o caso da cana, do cerrado e da mata. De uma forma geral, nos locais onde há maior potencial erosivo, há uma tendência de menor expectativa de perdas por erosão pela existência de usos, tais como cana, cerrado, mata e, em alguns casos, até o pasto. Em áreas muito restritas, onde ocorre menor potencial erosivo, de fraco a moderado, passou a haver maior expectativa de perdas por erosão, nesse caso, motivado principalmente pela ocorrência de culturas temporárias e pelo coco.

Os valores de perdas relativas de solos verificados no plano de informação de PR, embora sejam considerados neste trabalho de forma apenas para avaliar as áreas de maior ou menor expectativa de erosão, apresentam uma forte concentração nos valores mais baixos, indicando que há, com as categorias de uso da terra existentes, uma baixa perda de solo pela erosão laminar.

De acordo com as observações realizadas nos trabalhos de campo, foi possível confirmar a tendência dos resultados obtidos pela aplicação do modelo EUPS, ou seja, não foram verificados problemas sérios de erosão na área de estudo, a não ser alguns sulcos e um processo de ravinamento ao norte do açude Pacatuba, exatamente onde existe maior expectativa de erosão.

Análise comparativa dos mapas de Perdas relativas por erosão, gerados a partir da EUPS e de técnica estatística multivariada

Buscou-se elaborar mapa de Perdas relativas por erosão a partir de método estatístico multivariado (análise das correspondências), que possibilitasse o uso de dados nas escalas nominal e ordinal, utilizando as variáveis utilizadas no modelo EUPS. O resultado obtido com o referido modelo é utilizado como referência para avaliar o resultado obtido com o método estatístico. 
$\mathrm{O}$ arquivo de dados foi construído no programa Excel e exportado para o programa MVSP versão de teste 3.11a - obtido pela Internet (Multivariate Software Package - Kovach Computing Services). A opção pelo programa foi feita considerando sua eficiência, praticidade e simplicidade, comparado com outros programas disponíveis.

No programa MVSP foi utilizada a opção de análise das correspondências, considerando a identificação das células (linhas) como casos e os parâmetros da EUPS (colunas) como variáveis. Foi obtido resultado para os três primeiros eixos, para os quais os autovalores e percentuais de contribuição foram, respectivamente: Eixo I - 0,294 e 7,742 \%; Eixo II - 0,251 e 6,616 \%; Eixo III-0,233 e 6,131\%.

Utilizando o programa Excel constatou-se que foram obtidos 141 valores de coordenadas para os 4361 casos referentes à área de estudo, já que, considerando também a área do quadro externo à mesma, totaliza 9984 células (96 linhas x 104 colunas). As 141 coordenadas dos casos e as 24 das variáveis foram dispostas num sistema de eixos ortogonais, levando em consideração os eixos I e II (Figura 8), conforme utilizado por Greenacre (1993) e também os eixos II e III. A disposição das coordenadas nos eixos II e III foi avaliada, levando em consideração a observação de Landim-Goya e Landim (1997), que utilizaram os referidos eixos para plotagem dos resultados considerando que os valores relativos ao primeiro eixo é sempre igual a 1,00, como conseqüência da dupla transformação e subseqüente reescalonamento empregado. Entretanto, observou-se, que pelo menos pela disposição dos dados nos eixos fatoriais, a utilização dos eixos I e II apresentou melhor resultado, considerando a possibilidade de agrupamento de casos e variáveis. Portanto, levando em consideração a disposição das coordenadas nos eixos fatoriais, procurou-se agrupar os casos tomando como referência as variáveis, de modo que possibilitasse construir um mapa no qual as classes exprimissem as perdas relativas de solo, ou seja, que se assemelhasse ao mapa obtido com aplicação da EUPS. A separação das classes a partir dos eixos fatoriais pode ser observada na Figura 9. Isso é possível, especificamente como uma vantagem da técnica utilizada, em relação a outras técnicas semelhantes, uma vez que são verificados, ao mesmo tempo, tanto as relações entre indivíduos (casos) como entre as suas propriedades (variáveis) (LANDIM-GOYA E LANDIM, 1997). 


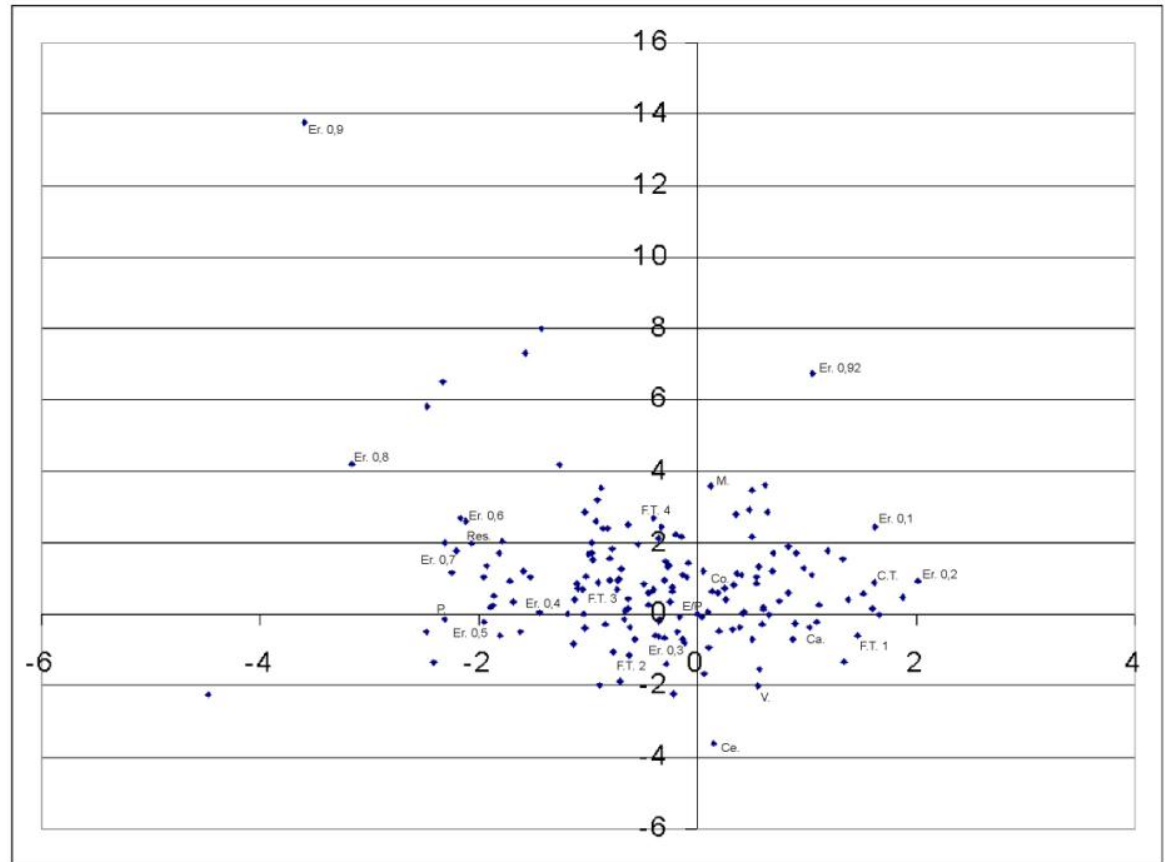

Figura 8 - Resultado da análise das correspondências para os dados utilizados na Equação Universal de Perdas de Solo.

Definição das classes do mapa de perdas relativas de solo a partir da análise das correspondências

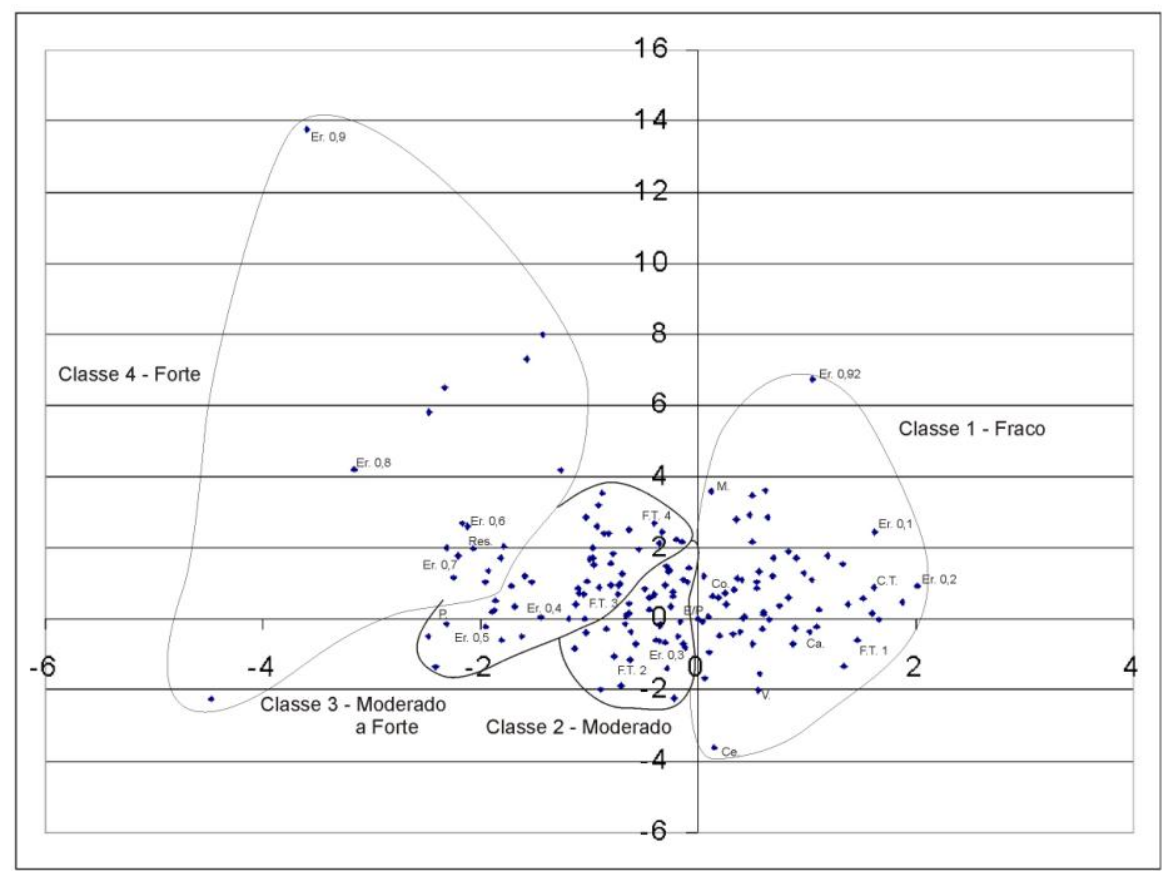

\section{Legenda}

E/P - Erosividade e Práticas conservacionistas Er. 0,1 - Erodibilidade 0,1 Er. 0,2 - Erodibilidade 0,2 Er. 0,3 - Erodibilidade 0,3 Er. 0,4 - Erodibilidade 0,4 Er. 0,5 - Erodibilidade 0,5 Er. 0,6 - Erodibilidade 0,6 Er. 0,7 - Erodibilidade 0,7 Er. 0,8 - Erodibilidade 0,8 Er. 0,9 - Erodibilidade 0,9 Er. 0,92 - Erodibilidade 0,92 F.T. 1 - Fator Topográfico 1 F.T. 2 - Fator Topográfico 2 F.T. 3 - Fator Topográfico 3 F.T. 4 - Fator Topográfico 4

Ca. - Cana

Ce. - Cerrado Co. - Côco

C.T. - Culturas Temporárias

M. - Mata

P. - Pasto

Res. - Residencial

V. Várzea

Figura 9 - Definição das classes do mapa de perdas relativas de solo a partir da Análise das Correspondências.

As coordenadas dos casos (identificação das células), agrupadas em 4 classes, foram inseridas no sistema IDRISI, via teclado, possibilitando a construção do mapa (plano de informação) disposto na Figura 10. 


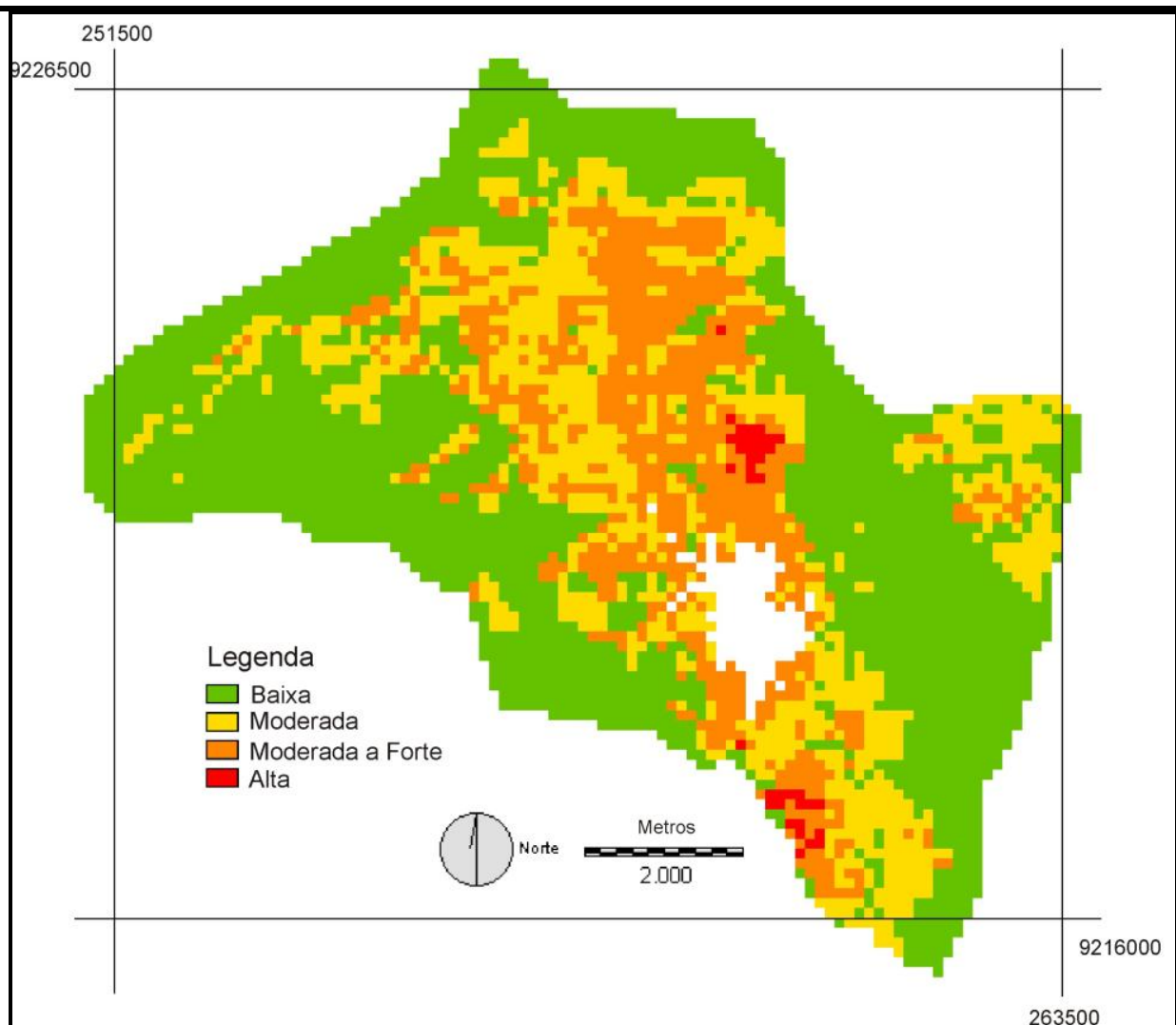

Figura 10 - Mapa de Perdas relativas por erosão obtido com a Análise das Correspondências.

Analisando inicialmente a definição das classes nos eixos fatoriais, pode-se verificar que as variáveis erodibilidade 0,9 , erodibilidade 0,92 e várzea não exerceram influência considerável, talvez porque ocorram em pequena proporção em relação às demais. A classe 1 foi definida como de baixa perda de solo, levando em consideração, preponderantemente, a influência das variáveis erodibilidade 0,1 e 0,2, fator topográfico 1, mata, cerrado e cana, sendo esses tipos de uso de média a elevada proteção do solo. Ressalte-se o fato de constar como influência para constituição dessa classe os tipos de uso culturas temporárias e coco, como sendo de baixa proteção do solo. De acordo com o mapa, realmente ocorre associação entre as referidas classes. Entretanto, pode-se observar ainda no mapa áreas de moderada perda de solo (classe 2 ) e de moderada a alta perda de solo (classe 3 ) em trechos de cerrado e de mata. No mapa gerado com o modelo EUPS ocorre em proporção muito pequena áreas de moderada perda de solo em trechos de cerrado. Nas áreas de mata a expectativa de perda de solo é sempre baixa.

Na classe 2 (moderada perda de solo) foi considerada a influência das variáveis erodibilidade 0,3 e fator topográfico 2 , ou seja, uma forte influência de fatores ligados aos aspectos do meio físico e quase nenhuma influência do uso da terra. No mapa, entretanto verifica-se 
correspondência entre as áreas de moderada perda de solo com a de erodibilidade 0,3 , fator topográfico 2 e também de pasto.

A classe 3 (moderada a alta perda de solo), de acordo com a análise das correspondências, foi concebida com influência das variáveis fator topográfico 3 e 4, erodibilidade 0,4 e 0,5 e pasto. Observando o mapa, constata-se uma boa correspondência entre as referidas classes. Entretanto, existem trechos das classes fator topográfico 3 e 4 que não correspondem às áreas de moderada a alta perda de solo.

Quanto à classe 4 (alta perda de solo), foi concebida considerando a influência das variáveis erodibilidade 0,6, 0,7 e 0,8 e do uso residencial. No mapa, essa classe ocorre de forma muito restrita e corresponde às variáveis consideradas referentes à erodibilidade. A variável de uso residencial está associada à classe 3 (moderada a alta perda de solo).

Analisando o mapa gerado pela análise das correspondências, verifica-se que, de certa forma, há coerência no resultado apresentado. Em comparação com o mapa gerado com o modelo EUPS, apresenta, em termos de dimensão espacial das classes de perdas de solo, uma geral atenuação das expectativas de perda, principalmente com relação às áreas de alta perda de solo. A observação feita com relação ao mapa gerado com o modelo EUPS, referente à constatação da baixa expectativa de perdas de solo na área de estudo, é corroborada e até enfatizada com o mapa gerado pela análise das correspondências.

Observa-se, entretanto, que o mapa gerado com o referida técnica estatística não apresenta como resultado uma nítida associação das classes existentes nos mapas que foram integrados, como ocorre com o mapa gerado pelo modelo EUPS, que é resultado de uma simples operação multiplicativa feita célula a célula.

A geração do mapa com a aplicação da análise das correspondências depende da forma como as classes do mapa são constituídas pela disposição das coordenadas dos casos e variáveis nos eixos fatoriais.

Com o objetivo de comparar os mapas de perdas relativas de erosão do solo foi utilizada a técnica da tabulação cruzada disponível no IDRISI, a partir da qual são obtidos relatórios com dados estatísticos e mapa (Figura 11), indicando a correspondência existente entre as classes dos dois mapas. 
Tabulação cruzada dos mapas gerados a partir da análise das correspondências (colunas) e do modelo EUPS (linhas):

\begin{tabular}{|c|c|c|c|c|c|c|c|c|}
\hline & 0 & 1 & 2 & 3 & 4 & To & & \\
\hline 01 & & 5622 & 0 & 0 & 4 & 01 & 562 & \\
\hline $1 \mid$ & 0 & 1406 & 272 & 123 & 7 & & 1 & 1808 \\
\hline 21 & 0 & 666 & 654 & 155 & 0 & & i & 1475 \\
\hline 31 & 0 & 199 & 110 & 398 & 9 & & 1 & 716 \\
\hline 41 & 0 & 143 & 50 & 144 & 22 & & i & 35 \\
\hline
\end{tabular}

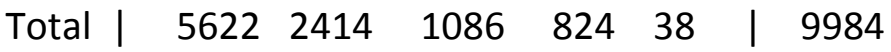

Mapa obtido com modelo EUPS em relação ao mapa gerado pela Análise das Correspondências

\begin{tabular}{|c|c|}
\hline Classe & KAPPA \\
\hline 0 & 0.9984 \\
\hline 1 & 0.7068 \\
\hline 2 & 0.3755 \\
\hline 3 & 0.5159 \\
\hline 4 & 0.0577 \\
\hline
\end{tabular}

Mapa obtido com Análise das Correspondências com relação ao mapa gerado com o modelo EUPS

\begin{tabular}{|c|c|}
\hline Classe & KAPPA \\
\hline 0 & 1.0000 \\
\hline 1 & 0.4901 \\
\hline 2 & 0.5333 \\
\hline 3 & 0.4431 \\
\hline 4 & 0.5632 \\
\hline
\end{tabular}

Índice Kappa geral - 0.6944 


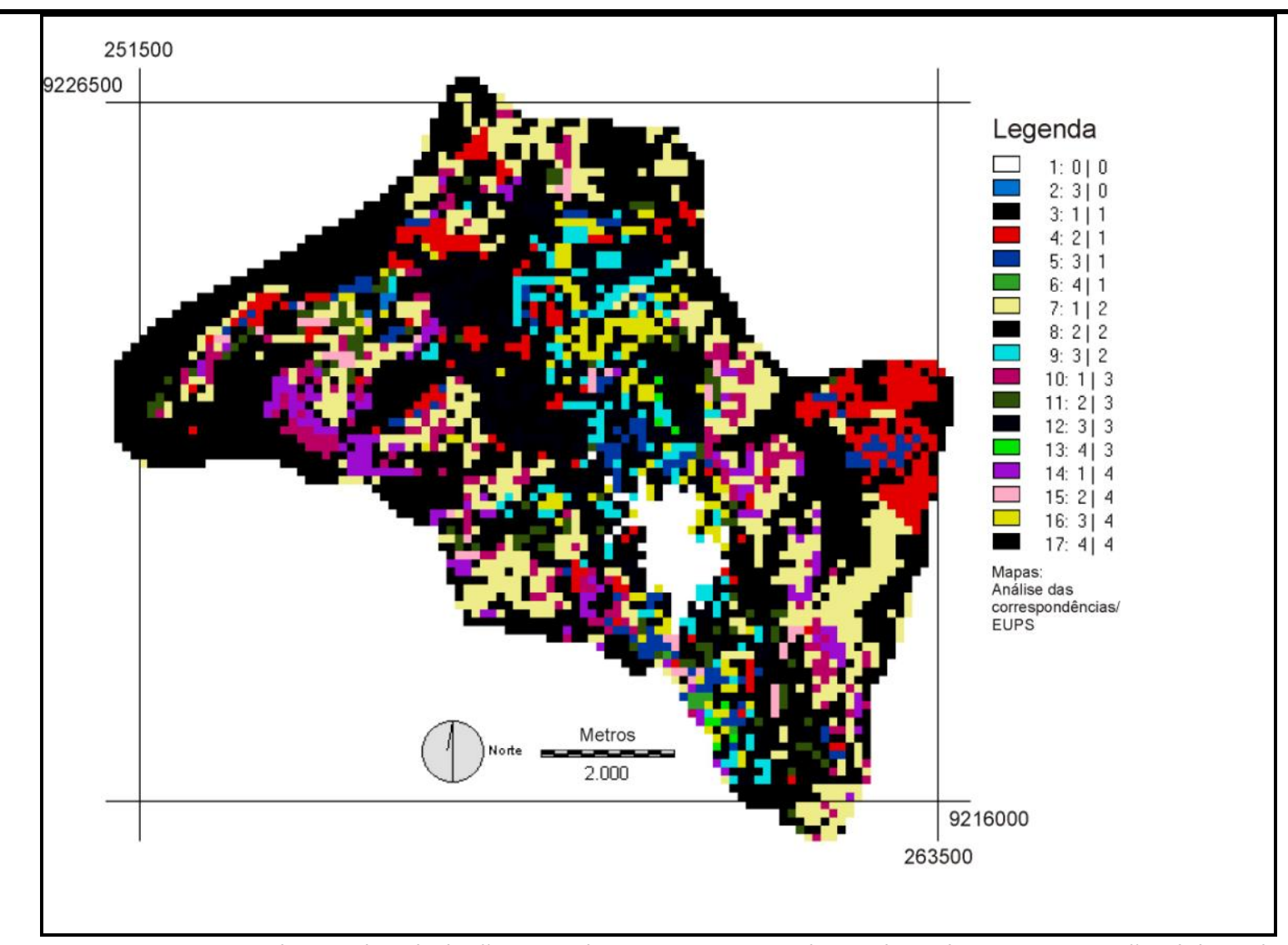

Figura 11 - Mapa resultante da tabulação cruzada entre os mapas de Perdas relativas por erosão elaborados com o modelo EUPS e com a Análise das Correspondências.

Considerando os dados estatísticos da tabulação cruzada, obteve-se o índice kappa geral no valor de 0,6944. Esse índice não pode ser considerado para efeito de análise comparativa porque leva em consideração o valor externo à área de estudo, que necessariamente é o mesmo para ambos os mapas, ou seja, zero. Entretanto, os dados podem ser analisados por categoria e por mapa. Pretende-se avaliar a semelhança que há entre o mapa obtido com a análise das correspondências em relação ao mapa obtido com o modelo EUPS. Assim, observa-se que existe uma semelhança média de todas as classes de 50,74 \%, e, para cada classe, também se observa uma semelhança de aproximadamente $50 \%$. Destaca-se que, apesar da pequena presença da classe 4 no mapa da análise das correspondências, apenas $56 \%$ das células correspondem com a classe 4 do outro mapa.

Com base no mapa de classificação cruzada (Figura 11), constata-se que a semelhança entre os mapas obtidos com a análise das correspondências e com o modelo EUPS, é mais nítida com relação à classe 1 (baixa perda de solo), até porque é a classe de maior representatividade espacial. Em trechos de ocorrência da classe 2 (moderada perda de solo) também se observa pontos de nítida semelhança entre os mapas. As classes 3 (moderada a alta perda de solo) e 4 (alta perda de solo) não apresentam uma semelhança tão nítida como 
as demais, uma vez que essa semelhança tem expressão espacial bastante pulverizada e as classes têm em ambos os mapas menor representatividade espacial.

\section{CONCLUSÕES}

O uso da Equação Universal de Perdas de Solo (EUPS) para gerar modelos espaciais preditivos é de simples aplicação, desde que se tenham disponíveis os dados dos fatores envolvidos na formulação. Os resultados obtidos demonstram ser bastante satisfatórios, a despeito das restrições apresentadas ao modelo quanto ao reducionismo, à simplificação da problemática da erosão, bem como do uso de informações quantitativas que traduzam equivocadamente a representação dos parâmetros envolvidos nos processos erosivos.

Necessário se faz comentar sobre a forma de elaboração dos arquivos digitais referentes aos fatores da EUPS (entrada célula por célula), que se torna muito trabalhosa na medida em que a área de estudo se torna mais ampla. Havendo possibilidade e confiabilidade dos dados, é conveniente automatizar a geração dos planos de informação referentes aos fatores da EUPS, por meio de processo de digitalização e conversão de formatos, assim como do uso de imagens orbitais digitais, possibilitando uma melhoria na resolução espacial dos produtos e, conseqüentemente, da precisão da informação espacial. No presente trabalho foi necessária a entrada de dados por meio do teclado, haja vista a inserção de proposta metodológica do uso da análise geoestatística e também devido à análise comparativa que seria efetuada com método estatístico multivariante.

Vale salientar as vantagens oferecidas pelos sistemas de informação geográfica para integração da informação espacial. Especificamente no caso do sistema IDRISI, que permite, com muita propriedade, a aplicação de modelagem matemática, uma vez que dispõe de diversas ferramentas de tratamento matemático e estatístico da informação espacial.

Quanto à integração da informação espacial por meio da técnica estatística da análise fatorial das correspondências, foi possível sua utilização e o resultado se mostrou satisfatório considerando dois aspectos. O primeiro, diz respeito à possibilidade de uso de dados nominais (presença/ausência), sem a necessidade de que exista previamente uma lógica de integração da informação espacial, que, em alguns casos, realmente não se dispõe. O segundo motivo está relacionado à possibilidade da obtenção da informação das coordenadas dos indivíduos e das variáveis conjuntamente, num mesmo plano representado 
pelos dois eixos fatoriais selecionados. Isso permite identificar, justificar e alterar como são agrupados os indivíduos, ou seja, as unidades espaciais.

A limitação, ainda existente, no uso dessa técnica, é a quantidade de indivíduos no caso de grandes áreas, considerando que esses sejam representados por unidades espaciais de dimensões relativamente pequenas (dezenas a centenas de metros quadrados). Essa limitação pode ser contornada através da inclusão de novas possibilidades de tratamento estatístico multivariado nos sistemas de informação geográfica, a exemplo do que foi feito com a análise geoestatística, que ultimamente vem ganhando espaço em diversos SIG's, embora tenha sido desenvolvida já faz algumas décadas, de forma semelhante com as técnicas de análise fatorial.

$\mathrm{Na}$ comparação dos resultados obtidos com os dois procedimentos de integração da informação espacial, e considerando as diferenças dos métodos empregados, pode-se considerar que a análise das correspondências, na ausência de um modelo matemático aplicável a informações espacializáveis, e do uso de uma lógica de integração de dados a ser utilizada com um procedimento bastante simplificado da álgebra booleana, pode ser empregada como alternativa para obtenção de mapas-síntese de áreas ainda relativamente pequenas.

Em ambos produtos finais obtidos no trabalho (mapas de Perdas relativas por erosão do solo), verificou-se coerência, em confronto com a realidade observada na área de estudo, quanto à relativa baixa expectativa de ocorrência de processos erosivos. Justifica-se pelo fato de que a área não apresenta grandes trechos de relevo acidentado, e possui, de uma forma geral, solos de baixa erodibilidade.

Associado a isso, deve-se levar em consideração que as precipitações não possuem alto poder erosivo, e também os tipos de uso existentes exercem boa proteção ao solo.

Considerando as observações sobre os aspectos mais pertinentes do trabalho, entende-se que, de uma forma geral, os objetivos do mesmo foram plenamente atingidos.

\section{REFERÊNCIAS BIBLIOGRÁFICAS}

BENZÉCRI, J.-P. ET AL. (1976) L'Analyse des Données. Paris, Dunod, 2 v.

BENZÉCRI, J.-P. (1992) Correspondence analysis handbook. New York: Marcel Dekker, 2 v. 
BERTIN, J. (1980) O teste de base da representação gráfica. Revista Brasileira de Geografia.

Rio de Janeiro, 42(1): 160-182.

BERTONI, J. (1959) O espaçamento de terraços em culturas anuais, determinação em função das perdas por erosão. Bragantia, Campinas, SP, 18:113-40.

BERTONI, J. ; LOMBARDI NETO, F. (1993) Conservação do solo. 3.ed. São Paulo: Ícone.

BOROUCHE, J-M.; SAPORTA, G. (1982) Análise de dados. Zahar,Rio de janeiro, 116 pp.

BROSSARD, Thierry (1980) Classification hierarchique et cartographie experimentale. Bull. Assoc. Géog. Franç., Paris, no. 474, pp.363-371.

CARR, James R, (1990) Corspond: a çortable Fortran-77 program for correspondence analysis. Computers \& Geosciences Vol 16, no. 3, pp. 289-307.

CARVALHO, Maria Gelza R. F. de (1982) Estado da Paraíba: classificação geomorfológica. João Pessoa: Editora Universitária, UFPB, 72 p.

CASTRO, J.F.M. (1993) Aplicação de um Sistema de Informação Geográfica na Temática da Morfodinâmica: o exemplo do estudo da Bacia do Rio Mogi - Cubatão/SP. Dissertação de Mestrado, FFLCH/SP.

CASTRO, A.G.; VALÉRIO FILHO, M. (1997) Simulação da expectativa de perdas de solo em microbacia sob diferentes manejos florestais. R. bras. Ci. Solo, Viçosa, 21:419-26.

CAVALIERI, A. (1994) Erodibilidade do solo: avaliação por meio de propriedades físicas e químicas. Dissertação de Mestrado, UNICAMP.

CETESB (1991) Carta Morfodinâmica da Serra do Mar na Região de Cubatão - SP. Relatório Técnico. São Paulo.

CHAMUSSY, H.; CHARRE, J.; DUMOLARD, M.-G.; LE BERRE, (1980) Iniciación a los métodos estadísticos geografia. Barcelona, Editorial Ariel, 284 pp.

CHAVES, H. M. L. (1994) Adaptação do modelo WEPP para as condições brasileiras, In: Pereira, V. de P., Ferreira, M. E, e Cruz, M. C. P. da Solos altamente susceptíveis à erosão. Jaboticabal: FCAV - UNESP/SBCS, 213-21. 
CHRISMAN, W. R.; MEZERA, D.F.; MOYER, D.D.; NIEMANN Jr.; SULLIVAN, J.G. \& VONDEROHE, A.P. (1986) Soil erosion planning in Wisconsin: an application and evaluation of a multipurpose land information system. In: ACSM - ASPRS Annual Convention. Washington, DC: Mar, 16-21, 1986. Technical Papers. Falls Church, Virginia, 240-49.

CHRISTOFOLETTI, A. (1999) Modelagem de sistemas ambientais. São Paulo: Edgard Blücher.

COLE, J.P. (1972) Geografia Quantitativa. Rio de Janeiro, Instituto Brasileiro de Geografia e Estatística - IBGE.

DE BIASI, M. (1970) Carta de declividade de vertentes: confecção e utilização. Geomorfologia, IG, 21:8-12.

DE BIASI, M. (1992) A carta clinográfica: os métodos de representação e sua confecção. Revista do Departamento de Geografia, 6:45-60, FFLCH/USP.

DE PABLO, C.L.; GOMEZ SAL, A. \& PINEDA, F.D. (1987) Élaboration automatique d'une cartographie écologique et son évaluation avec des paramètres de la théorie de l'information. L'espace Géographique, no 2, 115-128 p.

DENARDIN, J.E. (1990) Erodibilidade do solo estimada por meio de Parâmetros físicos e Químicos. Tese de Doutorado, ESALQ-USP.

DUMAS, J. (1965) Relation entre l'érodibilité des sols et leurs caratéristiques analytiques. Cahiers Orstom, Paris: v.3, n.4, 307-33 (Sér. Pédologie).

EL-SWAIFY, S.A.; DANGLER, E.W. (1977) Erodibilities of selected tropical soils in relation to structural and hydrological para meters. In: National Conference on Soil Erosion, 30. 1976, West Lafayette, Proceedings... Ankeny: SWCS, 105-10.

FERREIRA, M.C. (1995) Análise Integrada de Dados Espaciais e Hidrológicos no Estado de São Paulo: uma metodologia baseada em Sistemas de Informação Geográfica. Tese de Doutoramento, FFLCH, USP.

FORMAGGIO, A.R.; ALVES, D.S.; EPIPHANIO, J.C.N. (1992) Sistemas de informações geográficas na obtenção de maps de aptidão agrícola e de taxa de adequação de uso das terras. R. bras. Ci. Solo, Campinas, 16:249-56. 
GOULD, P.R. (1967) On the geoqraphical interpretation of eigenvalues. Trans. Inst. British Geographers, no. 42, p. 53-86.

GREENACRE, M.J. (1993) Correspondence Analysis in Practice. London: Academic Press.

INSTITUTO DE PESQUISAS TECNOLÓGICAS DO ESTADO DE SÃO PAULO(IPT) (1986) Orientações para o combate à erosão no Estado de São Paulo, Bacia do PeixeParanapanema. São Paulo, 6v. (IPT, Relatório no. 24.739).

LANDIM, P.M.B. (1995) Análise estatística de dados multivariantes em geologia. Laboratório de Geomatemática, IGCE-UNESP-Rio claro, Publicação Didática $n^{\circ} 5$.

LANDIM-GOYA, Paula da Cruz \& LANDIM, Paulo M. B. (1997) Análise das correspondências para o tratamento de tabelas de dados. Geografia, Rio Claro, Vol. 22 (1):37-50.

LEGENDRE, Pierre; LEGENDRE, Louis (1998) Numerical Ecology; second english edition. Amsterdan: Elsevier Science B.V., 853 p. (Developments in Environmental Modelling, 20).

LEPRUN, J,C. (1981) A erosão, a conservação e o manejo do solo no nordeste do Brasil: balanço, diagnóstico e novas linhas de pesquisa. Recife, SUDENE, Departamento de Recursos Naturais, 105 p. (Brasil, SUDENE, Recursos de Solo, 15).

LEPRUN, J.C; SILVA, F.B.R. e (1994) Avaliação das perdas de solo e água por erosão no Nordeste semi-árido. In: Projeto Áridas, GT-I-Recursos Naturais e Meio Ambiente (Vol. 1.2 condições do uso e perspectivas de uso sustentável dos geoambientes do semi-árido), Seplan/PR.

LIMA, J.M, de (1987) Relação entre erosão, teor de ferro, parâmetros físicos e mineralógicos de solos da região de Lavras (MG). Dissertação de Mestrado, ESAL-UFLA.

LIMA, E.R.V.; CASTRO, J.F.M. \& DINIZ, J.A .F. (1996) Avaliação Estatística de Mapeamento da Morfodinâmica na Bacia do Rio Mogi - Cubatão/SP. Boletim de Geografia Teorética, vol. 26 (51-52).

LIMA, E.R.V. (1990) Mapa de risco de erosão do solo : Uma abordagem usando Sistema de Informações Geográficas e Imagens Orbitais. (Dissertação de Mestrado em Sensoriamento Remoto e Aplicações). São José dos Campos, INPE, Março, 1990. 
LIMA, J.M. de; CURI, N.; RESENDE, M. \& SANTANA, D.P. (1990) Dispersão do material de solo em água para avaliação indireta da erodibilidade de latossolos. R. bras. Ci. Solo, Campinas, $14: 85-90$.

LOAGUE, K; GANDER, G.A. (1990) R-5 revisited 1: spatial variability of infiltration on a small rangeland catchment. Water Resources Research 26:957-72.

LOMBARDI NETO, F. \& BERTONI, J. (1975) Erodibilidade de solos paulistas. Campinas, Instituto Agronômico, set, 12 p. (B.Tec. 27) .

MARTINELLI, M. (1991) Curso de cartografia temática. São Paulo: Contexto.

MOORE, IAN D.; TURNER, A.KEITH; WILSON, JOHN P.; JENSON, SUSAN K.; BAND, LAWRENCE E. (1993) GIS and Land-Surface-Subsurface Process Modeling. In: Environmental Modeling with GIS. Editado por: Michael F. Goodchild, Bradley O. Parks e Louis T. Steyaert. New York: Oxford Univeristy Press.

PAEZ, M. (1989) Evaluación de la erodibilidad y eficiencia de índices de erodibilidad en suelos agrícolas de Venezuela. Maracay: UCV, 1989. 146 p. (Tese - Doutorado em Ciência do Solo.

PINTO, S.A.F. (1983) Utilização de técnicas de sensoriamento remoto para a caracterização da erosão do solo no SW do Estado de São Paulo. Dissertação de Mestrado em Sensoriamento Remoto. São José dos campos, INPE, abril (INPE-2694-TDL/128) .

PINTO, S.A.F. (1991) Sensoriamento remoto e integração de dados aplicados no estudo da erosão dos solos. Tese de Doutorado, USP. 134 p.

RACINE, J.B.; REYMOND, H. (1973) L'analyse quantitative en géographie. Paris, P.U.F., 316 $\mathrm{pp}$.

ROMKENS, M.J.M.; ROTH, C.B. \& NELSON, D.W. (1977) Erodibility of selected clay subsoils in relation to physical and chemical properties. Soil Sci. Soc. Am. J., 41:954-60.

ROTH, C.B.; NELSON, D.W. \& ROMKENS, M.J.M. (1974) Prediction of subsoil erodibility using chemical, mineralogical and physical parameters. Washington: U.S. Environmental Protection Agency. 111 p. (EPA-660/2-74-043). 
SAADI, A. (1985) Contribuição da "Análise Fatorial das Correspondências - AFC" à resolução de alguns problemas de Geografia Física. Boletim de Geografia Teorética, 15(29-30):196-215.

SAMPAIO, José Benito Mattos de (1973) Levantamento de Reconhecimento Semidetalhado de Solos de Sapé, Mari e parte de Mamanguape, Mulungu e Caldas Brandão - Estado da Paraíba. Recife, SUDENE - Div. Documentação, 141 p.

SANCHEZ, M.C. (1993) A propósito das cartas de declividade. In: Simpósio de Geografia Física Aplicada, 5, 1993, São Paulo. Anais. São Paulo: Departamento de Geografia, FFLCH/USP, 311 14.

SILVA, João dos Santos Vila da (2003) Análise Multivariada em Zoneamento para Planejamento Ambiental - Estudo de Caso: Bacia Hidrográfica do Alto Rio Taquari MS/MT. Tese de Doutorado, Faculdade de Engenharia Agrícola, Universidade Estadual de Campinas, São Paulo.

SILVA, Jorge Xavier; SOUZA, M.J.L. (1987) Análise Ambiental. Rio de Janeiro, UFRJ.

THOMASSIN, M.-M. (1985) Analyse des données et representation cartographique; application aux conditions physiques et potentialites de la Sierra Équatorienne. Les Cahiers de l'Analyse des Données, Vol. X, no, I, 25-51 p.

VALENTE, J.M.G.P. (1982) Geomatemática: Lições de geoestatística. Fundação Gorceix, Vol. III.

VALENZUELA, C.R. (1988) ILWIS Overview. ITC Journal, (1):3-14.

VALENZUELA, C.R.; BAUMGARDNER, M.F. \& PHILLIPS, T.L. (1986) Soils an important component in a digital geographic information system. In: International Symposium on Remote Sensing for Resources Development and Environment Management, 7., Enshede, HetherInds, Aug. 25-29, 1986. Proceedings, Rotterdam, A.A. Balkema, 939-45.

VENTURA, S.J.; CHRISMAN, N.R.; CONNORS, K.; GURDA, R.F. \& MARTIN, R.W. (1988) A land information system for soil erosion control planning. Journal of Soil and Water Conservation, 43:230-33. 
WEBSTER, R. (1985) Quantitative spatial analysis of soil in the field. In: STEWART, B.A., ed. 1985. Advances in soil science. New York: Springer-Verlag. V.3, 1-70.

WIEBER, Jean-Claude (1980) Etablissement d'un modele regional de classification typologique des paysages. Bull. Assoc. Géog. Franç., Paris, no. 468. pp.125-129.

WISCHMEIER, W.H.; JOHNSON, C.B. \& CROSS, B.V. (1971) A soil erodibilitv nomogram for farmland an construction sites. Journal of Soil and Water Conservation, 26 (5):189-93.

WISHMEIER, W.H.; SMITH, D.D. (1978) Predicting rainfall erosion losses - a guide to conservation planning. Agriculture Handbook, n. 537, U.S. Department of Agriculture, Washington, $58 \mathrm{p}$.

YATES, S.R.; WARRICK, A.W. (1987) Estimating soil water content using cokriging. Soil Sci. Soc. of Am. J., 51:23-30.

ZUQUETTE, L.V. (1987) Análise crítica sobre cartografia geotécnica e proposta metodológica para as condições brasileiras. Tese de Doutoramento, EESC, São Paulo. 